\title{
Some substrates of P-glycoprotein targeting $\beta$-amyloid clearance by quantitative structure-activity relationship (QSAR)/membrane-interaction (MI)-QSAR analysis
}

\author{
Tongyang Zhu, Jie Chen, Jie Yang* \\ State Key Laboratory of Pharmaceutical Biotechnology, Life College, Nanjing University, Nanjing, China \\ Email: luckyjyj@sina.com.cn \\ Received 28 April 2013; revised 29 May 2013; accepted 15 June 2013 \\ Copyright (C) 2013 Tongyang Zhu et al. This is an open access article distributed under the Creative Commons Attribution License, \\ which permits unrestricted use, distribution, and reproduction in any medium, provided the original work is properly cited.
}

\begin{abstract}
The pathogenesis of Alzheimer's disease (AD) putatively involves a compromised blood-brain barrier (BBB). In particular, the importance of brain-to-blood transport of brain-derived metabolites across the BBB has gained increasing attention as a potential mechanism in the pathogenesis of neurodegenerative disorders such as AD, which is characterized by the aberrant polymerization and accumulation of specific misfolded proteins, particularly $\beta$-amyloid $(\mathrm{A} \beta)$, a neuropathological hallmark of AD. P-glycoprotein (P-gp), a major component of the $\mathrm{BBB}$, plays a role in the etiology of AD through $\mathrm{A} / \boldsymbol{\beta}$ clearance from the brain. Our QSAR models on a series of purine-type and propafenone-type substrates of P-gp showed that the interaction between P-gp and its modulators depended on Molar Refractivity, LogP, and Shape Attribute of drugs it transports. Meanwhile, another model on BBB partitioning of some compounds revealed that BBB partitioning relied upon the polar surface area, LogP, Balaban Index, the strength of a molecule combined with the membrane-water complex, and the changeability of the structure of a solute-membranewater complex. The predictive model on BBB partitioning contributes to the discovery of some molecules through BBB as potential AD therapeutic drugs. Moreover, the interaction model of P-gp and modulators for treatment of multidrug resistance (MDR) indicates the discovery of some molecules to increase $A \beta$ clearance from the brain and reduce $A \beta$ brain accumulation by regulating BBB P-gp in the early stages of $A D$. The mechanism provides a new insight into the therapeutic strategy for AD.
\end{abstract}

Keywords: P-Glycoproteins; Quantitative

\footnotetext{
*Corresponding author.
}

Structure-Activity Relationship; ATP-Binding Cassette Transporters; Multidrug Resistance; Blood-Brain Barrier

\section{INTRODUCTION}

Therapy for central nervous system (CNS) diseases requires drugs that can cross the blood-brain barrier (BBB) [1]. BBB not only maintains the homeostasis of the CNS, but also refuses many potentially important diagnostic and therapeutic agents from entering into the brain [2]. The pathological hallmarks of Alzheimer's disease (AD) are progressive brain atrophy and the accumulation of cortical senile plaques, formed by the aggregation of amyloid beta peptide $(\mathrm{A} \beta)$ [3], and neurofibrillary tangles (NFT), namely the self-assembly of hyperphosphorylated forms of the microtubule associated protein tau into fibers termed "paired helical filaments (PHFs)" [4,5]. The pathogenesis of AD's senile plaque and NFT lesions putatively involves a compromised BBB [6], which protects the brain against endogenous and exogenous compounds and plays an important part in the maintenance of the microenvironment of the brain [7]. The ability of drug permeating across BBB becomes critical in the development of new medicines, especially in the design of new drugs active in brain tissue. In particular, the importance of brain-to-blood transport of brain-derived metabolites across the BBB has gained increasing attention as a potential mechanism in the pathogenesis of neurodegenerative disorders such as Parkinson's disease (PD) [8] and AD characterized by the aberrant polymerization and accumulation of specific misfolded proteins, particularly A $\beta$. P-glycoprotein (P-gp or MDR1/ABCB1) is a 170-kDa transmembrane (TM) protein widely expressed from the epithelial cells of the intestine, liver, kidney, placenta, uterus, and testis to endothelial cells of the BBB [9]. It belongs to the ABC (ATP-binding cassette) transporter family and serves to pump exogenous substances 
out of the cells. The domain topology of P-gp consists of two homologous halves each consisting a TM domain preceding a cytosolic nucleotide binding domain. Each TM domain is composed of six TM $\alpha$-helix segments involved in efflux as well as in drug binding [10]. The $A B C$ transport protein P-gp, a major component of the $\mathrm{BBB}$, mediates the efflux of $\mathrm{A} \beta$ from the brain as well as is a major factor in mediating resistance to brain entry by numerous exogenous chemicals, including therapeutic pharmaceuticals [11]. P-gp plays a role in the etiology of $A D$ through the clearance of $\mathrm{A} \beta$ from the brain. Some drugs, such as rifampicin, dexamethasone, caffeine, verapamil, hyperforin, $\beta$-estradiol and pentylenetetrazole, were able to improve the efflux of $\mathrm{A} \beta$ from the cells via P-gp upregulation [12]. Meanwhile, some compounds have been shown to reverse the P-gp mediated multidrug resistance (MDR), including verapamil, adriamycin, cyclosporin, and dexverapamil [13]. Hartz et al. have shown that upregulating P-gp in the early stages of $\mathrm{AD}$ has the potential to increase $\mathrm{A} \beta$ clearance from the brain and reduce $\mathrm{A} \beta$ brain accumulation by a transgenic mouse model of AD (hAPP-overexpressing mice) [14]. Abuznait et al. have also elucidated the impact of P-gp up-regulation on the clearance of $\mathrm{A} \beta$ [12], which indicated that targeting $\mathrm{A} \beta$ clearance via P-gp up-regulation was effective in slowing or halting the progression of $\mathrm{AD}$ and there was the possibility of P-gp as a potential therapeutic target for AD.

P-gp at the BBB functions as an active efflux pump by extruding a substrate from the brain, which is important for maintaining loco-regional homeostasis in the brain and protection against toxic compounds [8]. P-gp is also discovered in various resistant tumor cells and expressed widely in many normal tissues and plays a very important role in drug ADME-Tox (absorption, distribution, metabolism, excretion, and toxicity). MDR is a matter of growing concern in chemotherapy. Cells which express the MDR phenotype can over-express efflux transporters after exposure to a single agent. As a result, these cells become resistant to the selective agent and cross-resistant to a broad spectrum of structurally and functionally dissimilar drugs. The drug efflux pump P-gp has been shown to promote MDR in tumors as well as to influence ADME properties of drug candidates [15]. P-gp is expressed at the $\mathrm{BBB}$, the blood-cerebrospinal fluid barrier, and the intestinal barrier, thus modulating the absorption and excretion of xenobiotics across these barriers. P-gp and its ligands (substrates and inhibitors) are therefore extensively studied both with respect to reversing MDR in tumors and for modifying ADME-Tox properties of drug candidates, such as CNS active agents [15]. P-gp possesses broad substrate specificity and the substrates include members of many clinically important therapeutic drug classes, including anti-HIV protease inhibitors, calcium channel blockers used in the treatment of angina, hypertension, antibiotics and cancer chemotherapeutics [16]. In this active efflux process, energy originating from ATP hydrolysis is directly consumed. Because of such a wide distribution of P-gp, if a drug such as quinidine or verapamil inhibits the function of P-gp, it will also inhibit the excretion of digoxin by P-gp's leading to increased plasma levels and toxicity due to digoxin. It is believed to be an important protective mechanism against environmental toxins. Since the function of P-gp always results in the lack of intracellular levels of the drug necessary for effective therapy, the overexpression of P-gp in certain malignant cells is always associated with MDR phenotype [17]. Although a low resolution structure of P-gp is obtained, its physiological function and mechanisms of MDR modulation are still not very clear [18]. It is well known that a large number of structurally and functionally diverse compounds act as substrates or modulators of P-gp, including calcium and sodium channel blockers, calmodulin antagonists and structural analogues, protein kinase $\mathrm{C}$ inhibitors, steroidal and structurally related compounds, indole alkaloids, cyclic peptides and macrolide compounds, flayanoids and miscellaneous compounds [19], which mostly share common structural features, such as aromatic ring structures and high lipophilicity. Some of them possess MDR reversing activity while only a small number of them have entered clinical study. Classification of candidate drugs as substrates or inhibitors of the carrier protein is crucial in drug development [20].

On the other hand, the prerequisite to cure neurological disorders is that the drug distribution in CNS can reach effectively therapeutic concentrations [2]. Usually, the high $\mathrm{BBB}$ penetration is needed for drugs that activate in brain. The molecule negotiating the BBB must go through cellular membranes comprised of a lipid bilayer. Until now, it is widely accepted that interaction of compounds with P-gp is a complex process and at this time the details of its mechanism of action are still the subject of hot debate. Although the experimental analysis of drug permeability is essential, the procedure of experiment is time consuming and complicated, a theoretical model of drug permeability is effective to give predictions. Membrane-interaction (MI)-QSAR (quantitative structure-activity relationship) method is a structure-based design methodology combined with classic intramolecular QSAR analysis to model chemically and structurally diverse compounds interacting with cellular membranes. Our modified MI-QSAR method that combines QSAR with solute-membrane-water complex simulating the BBB environment is more close to the body condition than MIQSAR and possesses higher ability to predict organic compounds across BBB [21]. There are several critical assumptions considered that can influence validity and correctness of any QSAR study as follows: the same 
mechanism of action of all studied analogs; a comparable manner of their binding to the receptor; correlation of binding to the interaction energies; correlation of measured biological activities to the binding affinities [22]. All the accuracy answer and research based on the above questions above may guarantee that proper and reliable relationships are obtained. However, different mechanisms and different binding sites may be involved in the case of MDR modulators. Several screening assays can help in the identification of substrates and inhibitors although they have both advantages and drawbacks, such as cytotoxity assays [23], inhibition of efflux assays [16], P-gpATPase activation assays, and drug transport assays [24].

The goal of a QSAR study is to find a means of predicting the activity of a new compound. If possible, a desirable goal is the understanding of the biology and chemistry that give rise to that activity and the consequential possibility of reengineering the compound to remove or enhance that activity. One successful example is the transformation of nalidixic acid with the help of QSAR into an important family of drug: the quinolone carboxylates, such as norfloxacin, fleroxacin, ciprofloxacin, and levofloxacin [25]. Since the method was established in the 1960s, QSAR equations have been used to describe the biological activities of thousands of different drugs and drug candidates [26]. The method definitely provides a more accurate way to synthesize or filtrate the new chemical compounds. At last, the final destination is to degrade the cost of research and manufacture. To date, so many methods have been used in QSAR study and some of them have got successful results. There are general methods used in the literatures these years, such as multiple linear regression (MLR) method, partial least square regression (PLSR) [18], MI-QSAR analysis [21], 3D QSAR [27], and artificial neural network (ANN) [28]. In order to get more accurate results and QSAR models, we have used two different analyses: MLR and PLSR. Moreover, we focus on constructing theoretical models of the interaction between organic compounds and P-gp as well as the predictive models of BBB partitioning of organic compounds on the basis of QSAR analysis and MI-QSAR analysis.

\section{MATERIALS AND METHODS}

\subsection{P-Glycoprotein Ligands}

Building of some compounds. 36 purine derivatives were selected and used in QSAR analysis (Table 1) [29]. These compounds were divided into two sets: the training set and the test set. The study of the MDR-reversing properties of these derivatives was carried out in vitro on P388/VCR-20 cells, a murine leukemia cell line whose resistance was induced by vincristine (VCR), and KB-A1 cells, a human epidermoid carcinoma cell line whose resistance was induced by adriamycin (ADR). The compounds were tested at four concentrations $(0.5-5 \mu \mathrm{M})$ in association with VCR (P388/VCR-20 cells) or ADR (KBA1 cells). In this test, MDR ratio in P388/VDR-20 and $\mathrm{KB}-\mathrm{A} 1$ in vitro was used as biological activity for the whole dataset, namely $\mathrm{MDR}_{\text {ratio }}=\frac{\mathrm{IC}_{50}(\mathrm{CD})}{\mathrm{IC}_{50}(\mathrm{CD}+\mathrm{mod})}$.

Here "CD" is the abbreviation for cytotoxic drug (such as VCR and ADR) in cytotoxity assays, and "mod" means modulators. It is defined as ratio between the $\mathrm{IC}_{50}$ values (concentration that inhibits the growth of MDR cells by $50 \%$ ) of the cytotoxic agent in absence and presence of relatively nontoxic concentration of the modifier [23]. Most often the $\mathrm{IC}_{50}$ for several concentration of a cytotoxic drug is evaluated in the presence and absence of a nontoxic concentration of a P-gp modifier. In this assay modulators that interacted with P-gp and thus reduced the efflux of the cytotoxic compounds would increase the apparent toxicity of the cytotoxic compound [16]. The $\mathrm{IC}_{50}$ data were based on a general assessment of cytotoxicity and thus might account for more then one acting mechanism in the resistant cells used [16]. Furthermore, it is well known that the MDR ratio for any given compound can vary greatly depending on the cell type used for the assay as well as the intrinsic cytotoxicity of the compounds used. The data is also dependent on the concentration of the P-gp substrates or modulators used in the studies [30].

Similarly, another 21 propafenone analogs were selected from the literature of Diethart Schmid et al. and used in QSAR analysis (Table 2) [31]. In this test Ka of P-gp ATPase in the adriamycin-resistant subline CCRF ADR5000 was used as biological activity for the whole dataset [31]. The assays were performed based on the colorimetric determination of inorganic phosphate released by the hydrolysis of ATP. Table 2 shows all the structures and the experimental biological activity value.

Finally, all two-dimensional (2D) structures of these compounds mentioned above were constructed using the chemical drawing software ChemDraw 8.0 and prepared for the next calculation.

Calculation of some descriptors. Molecular descriptors are "numbers that characterize a specific aspect of the molecular structure" [32]. There are some molecular descriptors used in QSAR studies as follows: physicochemical properties (i.e. hydrophobicity, aqueous solubility, molecular electronegativity, and molecular refractivity), quantum chemical parameters (e.g. atomic charges, energies of HOMO (highest occupied molecular orbital) and LUMO (lowest unoccupied molecular orbital)) [33], topological indexes (such as molecular connectivity indexes) [34], and other 3D descriptors. Molecular descriptors were mostly calculated by the commercial soft- 
Table 1. The structures and MDR ratios of 35 purine derivatives in the training/test sets.

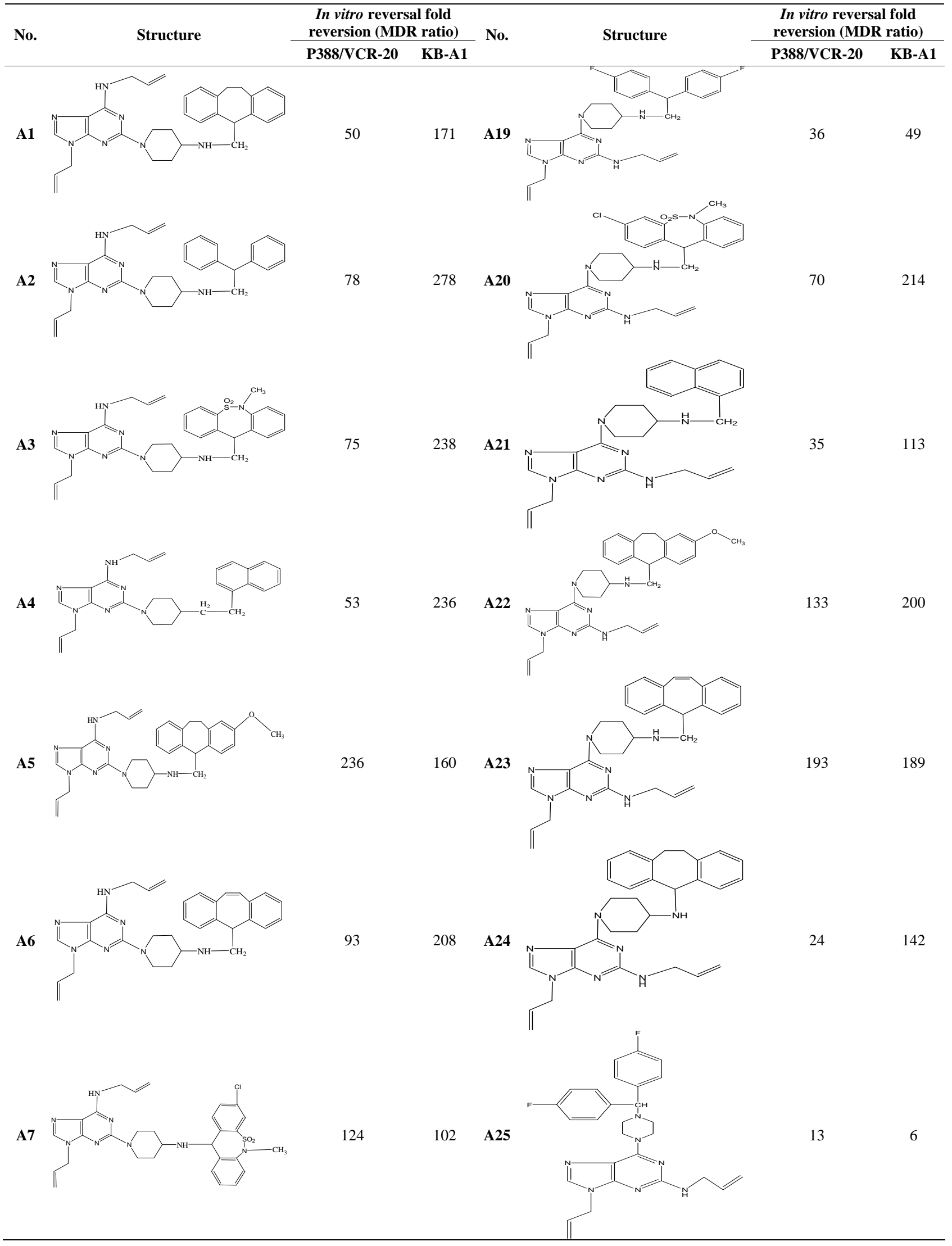




\section{Continued}

A8<smiles>C=CCNc1nc(N2CCC(NCC3c4ccccc4Cc4ccccc43)CC2)nc2c1cnn2CC=C</smiles>

A9<smiles>C=CCNc1nc(N2CCC(NCC)CC2)nc2c1ncn2CCC</smiles><smiles>C=CCCN1C=CC2C1=NC(N1CCC(NC[C@H]3c4ccccc4Cc4cc(C)c(C)c(C)c4[C@H]3C)CC1)=C[C@@H]2NCC=C</smiles><smiles>C=CCNc1nc(N2CCC(NC3c4ccccc4Oc4ccccc43)CC2)nc2c1ncn2CC=C</smiles>

A12<smiles>C=CCNc1nc(N2CCC(NC3c4ccccc4Cc4ccccc43)CC2)nc2c1ncn2CC=C</smiles>

A13<smiles>C=CCNc1nc(N2CCC(NCC3CCCCc4ccccc43)CC2)nc2c1ncn2CC=C</smiles>

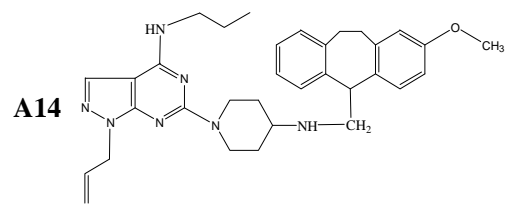

A15

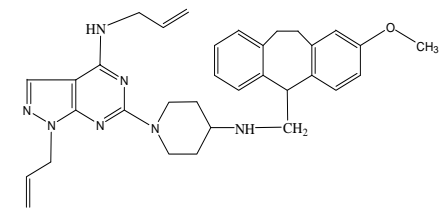<smiles></smiles>

30

57

108

37

15

78

56

75

51
120<smiles>C=CCCC1C=Cc2c1cc(N1CCN(c3ccc(F)cc3)CC1)nc2N(c1ccc(F)cc1)c1ccc(F)cc1</smiles>

75<smiles>C=CCNc1nc(N2CCC(NCC3c4ccccc4Oc4ccccc43)CC2)nc2c1ncn2CCC</smiles>

136

A28<smiles></smiles>

57

44<smiles>C=CCNc1nc(N2CCC(NC(C)C3c4ccccc4Cc4ccccc43)CC2)nc2c1ccn2CCC</smiles>

108

723

370

83<smiles>C=C(CC)C(C#CNC1CCC(C2CC3C(CCC)C=CC3[C@@H](NCCC)C2)CC1)(C1=CC=CCC1)C1=CC=CCC1</smiles>

272

A31<smiles></smiles>

147

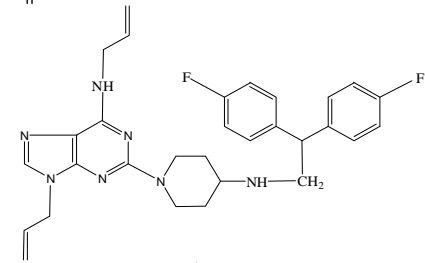

59 121

152

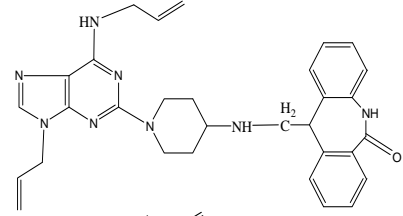

71

499

209

A34<smiles>C=CCNc1nc(N2CCC(NCC3c4ccccc4Cc4ccccc43)CC2)nc2c1nnn2CCCC</smiles>

9

27

6

23




\section{Continued}

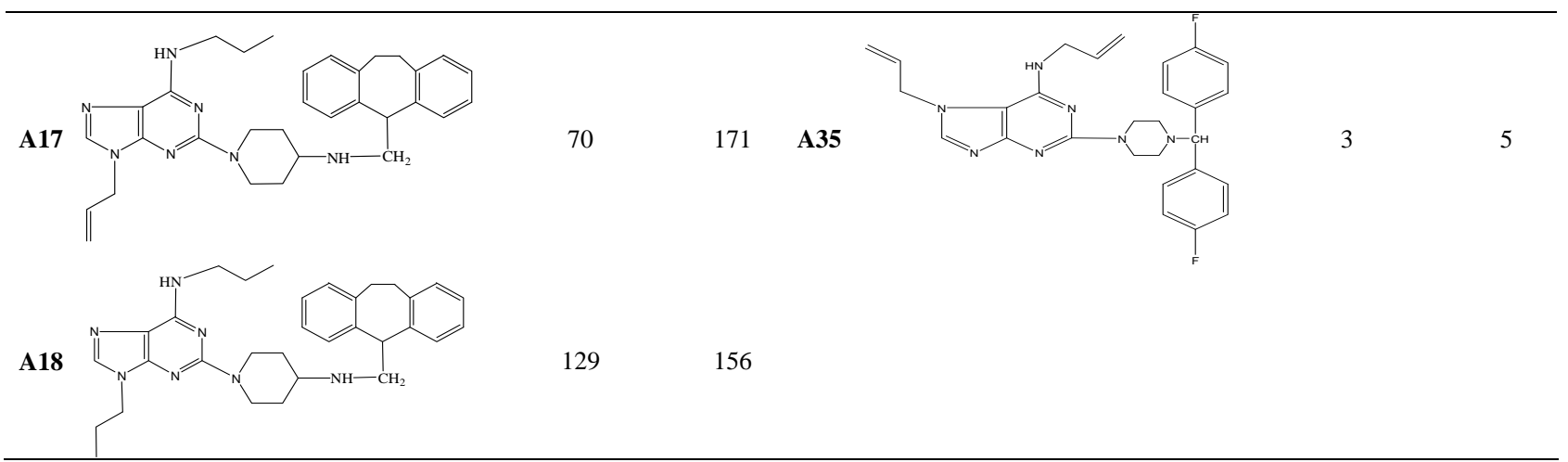

Note: Ratio of $\mathrm{IC}_{50}$ (cytotoxic alone (VCR for P388/VCR-20, ADR for KB-A1 cells))/IC 50 (cytotoxic + modulator) $(1 \mu \mathrm{M}$ in association with VCR or $2.5 \mu \mathrm{M}$ in association with ADR) [29].

Table 2. The structures and Ka values and LogP of 18 propafenone analogs in the training/test sets.

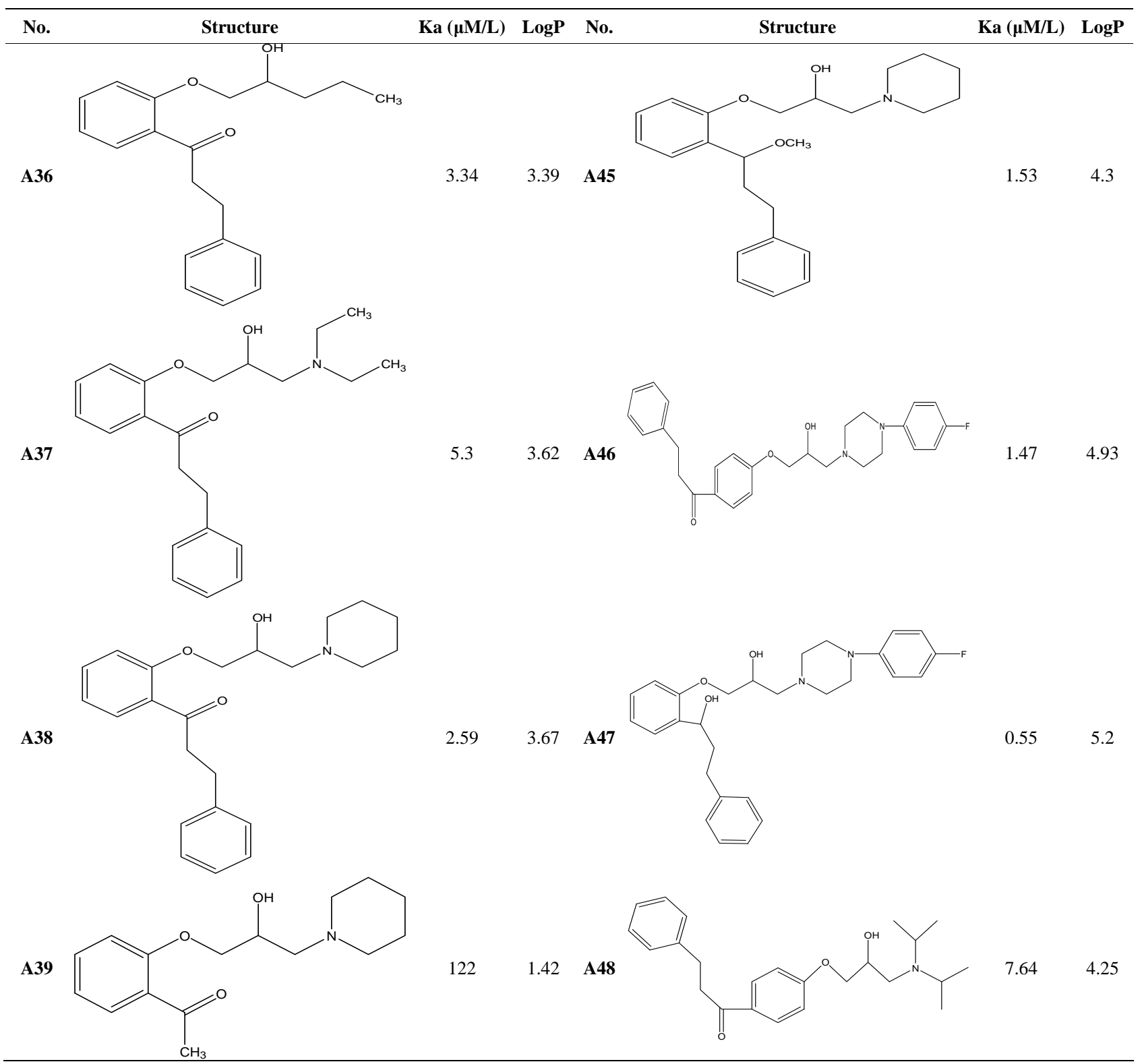




\section{Continued}

A40<smiles>O=C(CCc1ccccc1)c1ccccc1OCC(O)CN1CCN(c2ccc(F)cc2)CC1</smiles>

A41<smiles>CC(=O)c1ccccc1OCC(O)CN1CCN(c2ccc(F)cc2)CC1</smiles>

6.13

2.67

A50<smiles>CC(C)N(CC(O)COc1ccccc1C(O)CCc1ccccc1)C(C)C</smiles>

120

0.94<smiles>CCC(=O)c1ccccc1OCC(O)CN1CCC(C)(O)CC1</smiles>

18.5

$2.54 \quad$ A52<smiles>OC(COc1ccccc1C(O)CCc1ccccc1)CN1CCCCC1</smiles>

3.98

A53

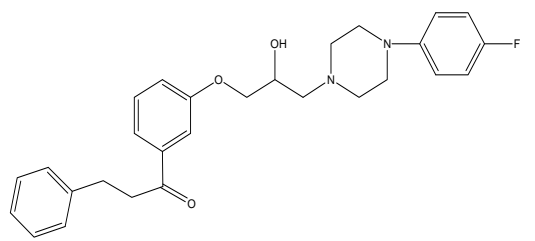

ware packages Chemoffice Chem3D Ultra 8.0, involving molecular mechanism parameters (Stretch-Bend Energy ( $\left.E_{\text {stretch }}\right)$, Bending Energy ( $\left.E_{\text {bend }}\right)$, Torsion Energy ( $\left.E_{\text {torsion }}\right)$, Total Energy ( $\left.E_{\text {total }}\right)$, van der Waals Energy ( $\left.E_{\mathrm{VDW}}\right)$, etc), quantum chemistry parameters (i.e. Electronic Energy
( $E_{\text {electronic }}$ ), HOMO Energy ( $\mathrm{E}_{\text {HOMO }}$ ) and LUMO Energy $\left(\mathrm{E}_{\mathrm{LUMO}}\right)$ ), hydrophobic parameters (such as ClogP), stereo parameters (eg. Es, Balaban Index (BI), Connolly Accessible Area (CAA), Molecular Weight (MW), Shape Attribute (ShA), Total Connectivity $\left(\mathrm{T}_{\text {con }}\right)$, and Wiener 
Index (WI)), thermodynamic parameters, including Henry’s Law Constant $(H)$, Hydration Energy $\left(E_{\text {hyd }}\right)$, Logarithm of partition coefficient in n-octanol/water (LogP), Molar Refractivity (MR), and molecular polar surface area (PSA) that defined as the surface area $\left(\AA^{2}\right)$ occupied by polar atoms, usually oxygen, nitrogen and hydrogen attached to them, which will restrict molecule penetration into the membranes [2]. The other properties involved in number of hydrogen bond acceptor (NBA) and number of hydrogen bond donor (NBD).

The energy parameters root in the results of molecular mechanism and molecular dynamics. The total energy of a system expressed as follows [35]: $E_{\text {total }}=E_{\text {valence }}+$ $\mathrm{E}_{\text {crossterm }}+\mathrm{E}_{\text {nonbone. }}$. Here, the valence interactions includes bond stretching (bond), valence angle bending (angle), dihedral angle torsion (torsion), and inversion, also called out-of-plane interactions (oop) terms, which are part of nearly all forcefields for covalent systems. A Urey-Bradley term (UB) may be used to account for interactions between atom pairs involved in 1 - 3 configurations (i.e., atoms bound to a common atom): $\mathrm{E}_{\text {valence }}=\mathrm{E}_{\text {bond }}+\mathrm{E}_{\text {angle }}$ $+E_{\text {torsion }}+E_{\text {oop }}+E_{U p}$. Modern (second-generation) forcefields generally achieve higher accuracy by including cross terms to account for such factors as bond or angle distortions caused by nearby atoms. Crossterms can include the following terms: stretch-stretch, stretch-bendstretch, bend-bend, torsion-stretch, torsion-bend-bend, bend-torsion-bend, stretch-torsion-stretch. The interaction energy between non-bonded atoms is accounted by van der Waals (VDW), electrostatic (Coulomb), and hydrogen bond (hbond) terms in some older forcefields. $\mathrm{E}_{\text {non-bond }}=\mathrm{E}_{\mathrm{VDW}}+\mathrm{E}_{\text {Coulomb }}+\mathrm{E}_{\mathrm{hbond}}$. Restraints that can be added to an energy expression include distance, angle, torsion, and inversion restraints. Restraints are useful for information on restraints and their implementation and use if you are interested in only part of a structure, and so is the documentation for the particular simulation engine.

These descriptors were calculated using Chemoffice Chem3D Ultra 8.0 and Hyperchem 7.5 as follows: 1 ) the structures of the compounds were drawn in ChemDraw 8.0 and sequentially changed to 3D structures by Chem3D; 2 ) the chosen compounds were minimized by molecular mechanism using MM2 force field with RMS (root mean square) gradient of 0.100 ; and 3 ) under the menu of Analyze-compute properties, the properties were selected to calculate and finally every descriptor value of each compound was gotten.

QSAR models. QSAR models of some purine derivatives (Table 1) were achieved by partial sum of squares for regression with software SPSS 10.0. A training set of 26 structurally diverse purine derivatives are measured is used to construct QSAR models. The QSAR models are optimized using MLR fitting and stepwise method (Eqs.15). A test set of five compounds is evaluated using the
QSAR models as part of a validation process. Take MDR ratio in vitro in P388/VDR cell lines as dependent variable and molecule descriptors as independent variable. With the aid of Virtual Computational Chemistry Laboratory software [20], QSAR modeling was constructed by PLSR (Eq.6).

Similarly, a training set of 18 structurally diverse propafenone analogs (Table 2) are measured is used to construct QSAR models. The QSAR models are optimized using MLR fitting and stepwise method (Eqs.711). Another QSAR modeling was constructed by PLSR (Eq.12). A test set of five compounds is evaluated using the QSAR models as part of a validation process.

\subsection{Blood-Brain-Barrier}

Data. 37 organic compounds [36,37] were elected to compose a train set while another 8 organic compounds were acted as a test set (Table 3). The dependent variable is the logarithm of the BBB partition coefficient, log $\mathrm{BB}=\log \left(\mathrm{C}_{\text {brain }} / \mathrm{C}_{\text {blood }}\right)$, where $\mathrm{C}_{\text {brain }}$ is the concentration of the test compound in the brain, and $\mathrm{C}_{\text {blood }}$ is the concentration of the test compound in blood. Experimental values of $\log B B$ published to date lie approximately between -2.00 to +1.04 . Compounds with $\operatorname{logBB}$ values of $>0.30$ are readily distributed to the brain whereas compounds with values $<-1.00$ are poorly distributed to the brain. Building of all these compounds was performed using the Build modules of Hyperchem 7.5. The geometry of these compounds was opitimized using the Amber 94 force field in gas state and sequentially placed at a periodic solvent box with a volume of $16 \times 10 \times 18 \AA^{3}$, which included 96 water molecules. Here, temperature is $300^{\circ} \mathrm{K}$ and pressure is 1 standard atmosphere. Then, the compounds in water were minimized by the above method and simulated by Monte Carlo method.

Molecular modeling of a dimyristoylphosphatidylcholine (DMPC) monolayer membrane complex with a layer of water. A model of DMPC monolayer membrane composed of 25 DMPC molecules $(5 \times 5 \times 1)$ was constructed using Material Studio and minimized for 200 steps with the smart minimizer. Here, the parameter of the single crystal of DMPC with $\mathrm{a}=8 \AA, \mathrm{b}=8 \AA$, and $\gamma$ $=96.0^{\circ}$ resulted in each lipid molecule with an average area of $64 \AA^{2}$ similar to Stouch's research results [38]. Moreover, a layer of water $\left(40 \times 40 \times 10 \AA^{3}\right)$ including 529 water molecules was added to the polar side of the DMPC monolayer membrane (Figure 1).

Molecular dynamic simulation of compound-DMPCwater complex models. A compound displaced a DMPC molecule in the DMPC monolayer membrane at three different positions (upper, center or lower) to form each solute-membrane-water complex. Molecular dynamic 
Table 3. The structures and LogBB values of some compounds in the training/test sets.

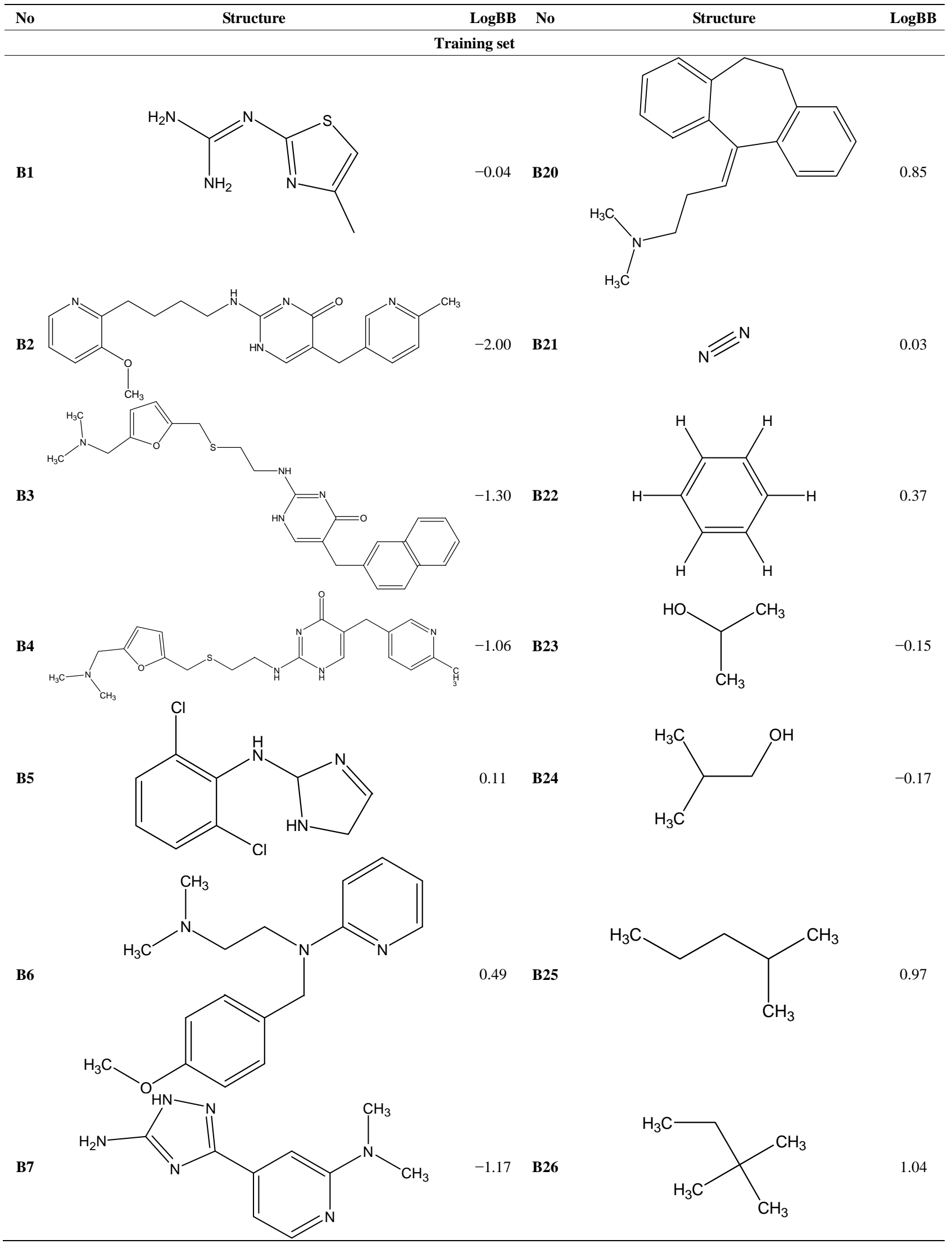




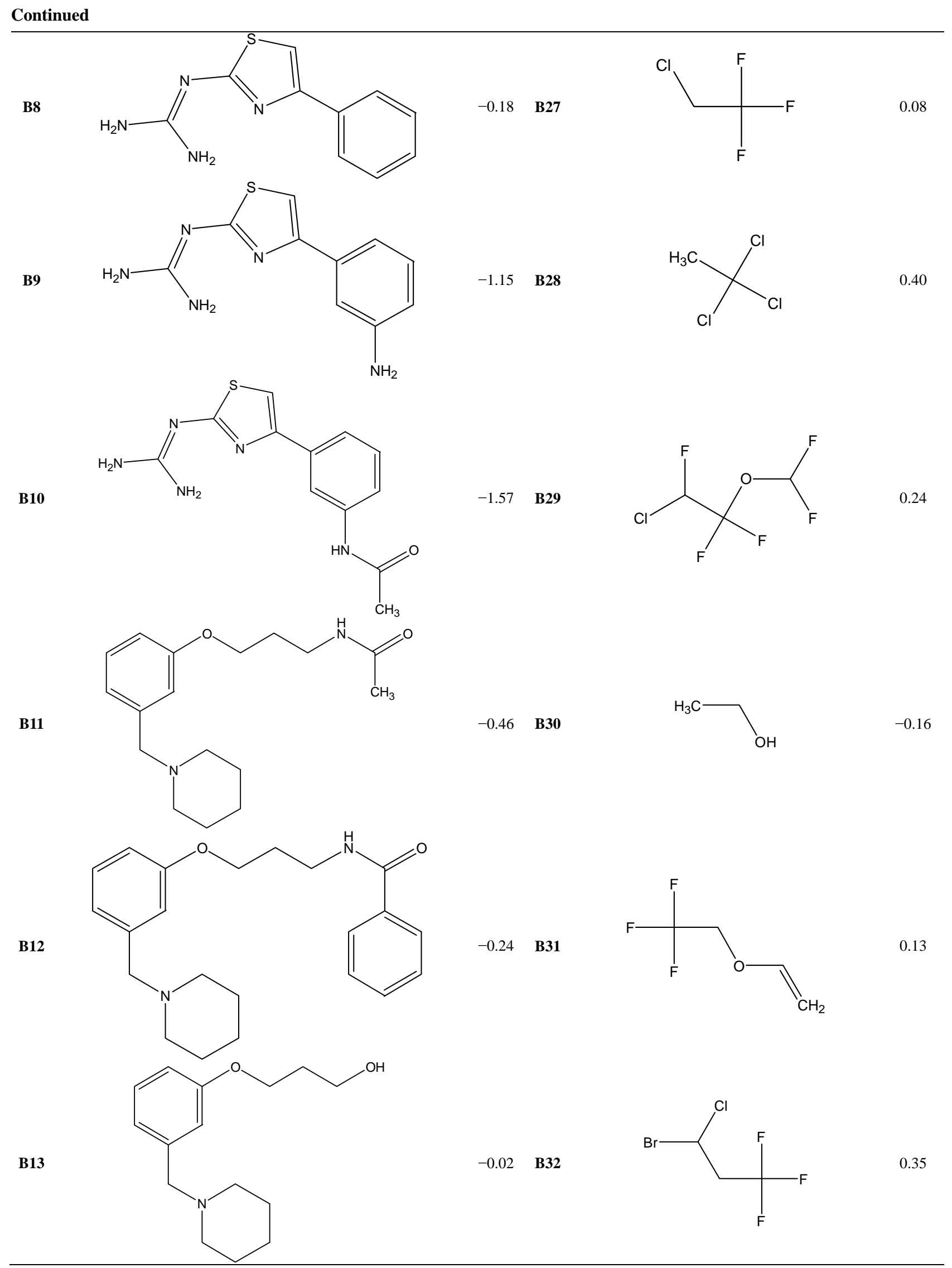




\section{Continued}

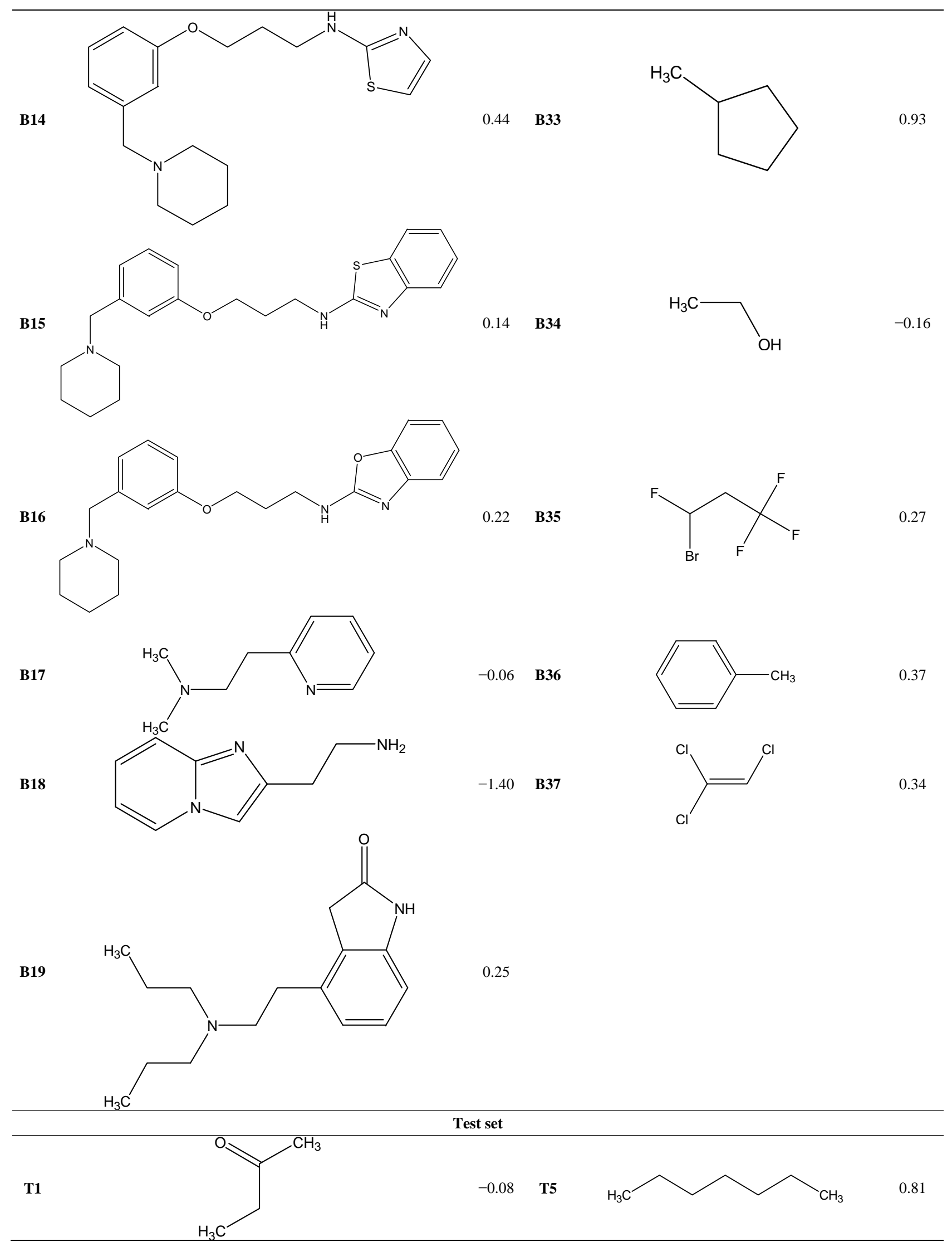




\section{Continued}

T2

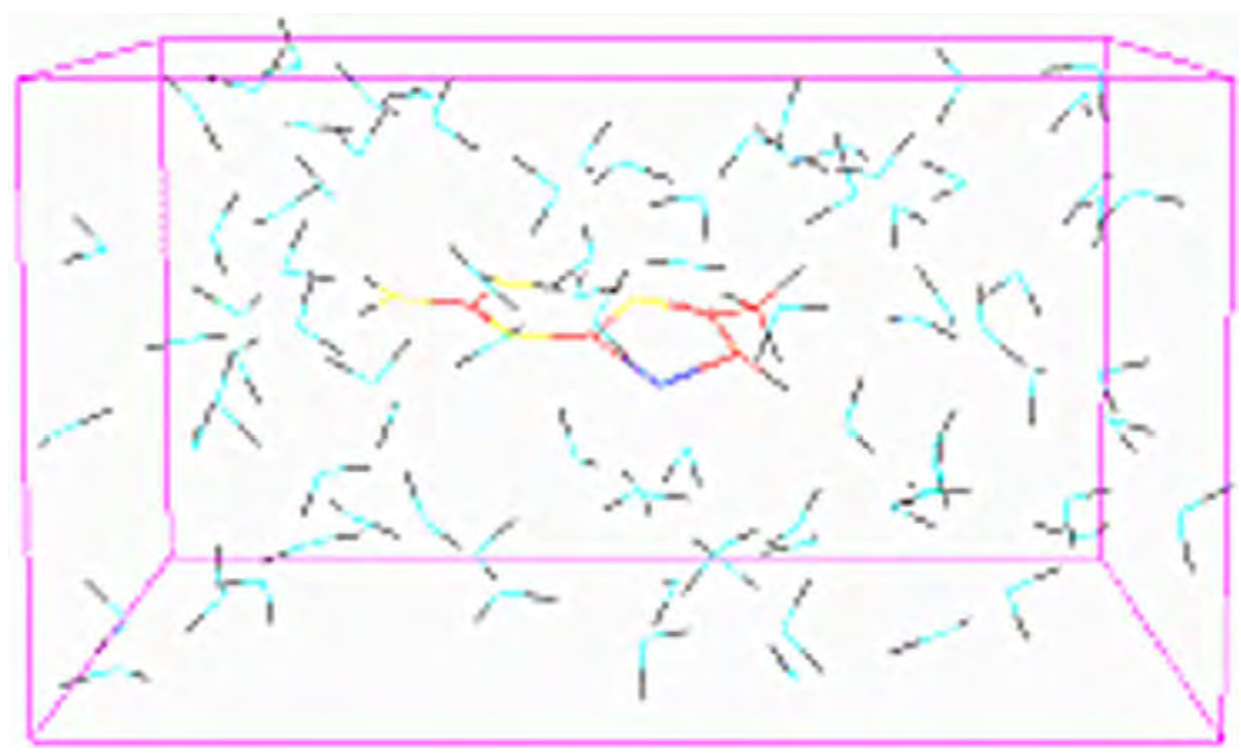

Figure 1. Compound B1 colored by atom-type in water and the solvent box defined in Monte Carlo simulation.

simulation of the complex was performed for 1000 steps by Discover module with Materials Studios, using Compass force field. Here, the $3 \mathrm{D}$ volume was restricted to a border of $\mathrm{X}=40 \AA, \mathrm{Y}=40 \AA, \mathrm{Z}=91.76 \AA$, and $\gamma=$ $96.0^{\circ}$.

QSAR model of BBB partitioning of some compounds. MI-QSAR model of a training set of 37 compounds through BBB were achieved by partial sum of squares for regression with SPSS. Molecular dynamics simulations were used to determine the explicit interaction of each compound with a model of DMPC monolayer membrane complexed with a layer of water. An additional set of intramolecular solute descriptors were computed and considered in the trial pool of descriptors for building MI-QSAR models. The MI-QSAR models were optimized using multidimensional linear regression fitting and stepwise method. The MI-QSAR models were then evaluated by a test set of 8 compounds.

\section{RESULTS}

\subsection{QSAR Analysis Based on MDR Ratio in P388/VDR-20 and KB-A1 in Vitro}

MDR ratio of compounds in vitro in KB-A1/ADR cell lines was taken as the dependent variable. A training set of 26 compounds (Table 4) was used to construct QSAR models. The QSAR models were optimized using MLR fitting and stepwise method by SPSS (Eqs.1-5). A test set of 5 compounds (A27-A31) was evaluated using the models as part of a validation process (Figure 2 upper, Table 5).

Similarly, MDR ratio of compounds in vitro in P388/ VDR cell lines acted as the dependent variable. With the aid of Virtual Computational Chemistry Laboratory software (http://vcclab.org) [20], some QSAR models were constructed by PLSR (Eq.6, Figure 2 down). Table 6 shows the calculated descriptors mentioned above and 
Table 4. The molecular descriptors of some compounds related to MDR ratios in the training/test sets.

\begin{tabular}{|c|c|c|c|c|c|c|c|c|c|c|c|}
\hline No. & LogMR & ShA & BI & $\log P$ & $E_{\text {hyd }}(\mathrm{kcal} / \mathrm{mol})$ & No. & LogMR & ShA & BI & $\log P$ & $E_{\text {hyd }}(\mathrm{kcal} / \mathrm{mol})$ \\
\hline \multicolumn{12}{|c|}{ Training set } \\
\hline A1 & 1.20 & 37.03 & $2,662,570$ & 3.33 & -3.56 & A14 & 1.22 & 39.02 & 3,358,755 & 1.48 & -19.64 \\
\hline A2 & 1.18 & 35.03 & $2,440,928$ & 2.59 & -13.71 & A15 & 1.22 & 39.02 & $3,358,755$ & 1.48 & -19.71 \\
\hline A3 & 1.22 & 40.02 & 3,649,082 & 1.14 & -16.23 & A16 & 1.20 & 37.03 & $2,662,570$ & 2.13 & -15.99 \\
\hline A4 & 1.14 & 32.03 & $1,669,953$ & 2.21 & -13.54 & A17 & 1.202 & 37.03 & $2,662,570$ & 2.13 & -16.23 \\
\hline A5 & 1.22 & 39.02 & $3,358,755$ & 1.33 & -19.71 & A18 & 1.202 & 37.03 & $2,662,570$ & 2.13 & -15.95 \\
\hline A6 & 1.20 & 37.03 & $2,662,570$ & 2.13 & -16.22 & A19 & 1.18 & 37.03 & 3,091,919 & 1.61 & -15.9 \\
\hline A7 & 1.22 & 40.02 & $3,491,392$ & 0.76 & -17.67 & A20 & 1.23 & 41.02 & $4,008,723$ & 0.76 & -17.36 \\
\hline A8 & 1.20 & 37.03 & $2,662,570$ & 2.28 & -16.3 & A21 & 1.14 & 32.03 & $1,651,352$ & 1.9 & -13.79 \\
\hline A9 & 1.24 & 42.02 & $4,491,514$ & 1.29 & -16.34 & A22 & 1.22 & 39.02 & $3,324,212$ & 1.33 & -20.06 \\
\hline A10 & 1.24 & 41.02 & 4,055,919 & 0.99 & -19.77 & A23 & 1.20 & 37.03 & $2,634,052$ & 2.13 & -15.77 \\
\hline A11 & 1.18 & 36.03 & $2,271,976$ & 1.41 & -17.73 & A24 & 1.19 & 36.03 & $2,246,188$ & 2.13 & -16.15 \\
\hline A12 & 1.19 & 36.03 & $2,271,976$ & 2.13 & -16.17 & A25 & 1.15 & 35.03 & $2,244,801$ & 1.71 & -14.88 \\
\hline A13 & 1.15 & 33.03 & $1,900,460$ & 2.28 & -13.57 & A26 & 1.15 & 35.03 & $2,271,261$ & 1.71 & -15.03 \\
\hline \multicolumn{12}{|c|}{ Test set } \\
\hline A27 & 1.19 & 37.03 & $2,662,570$ & 1.41 & -18.09 & A30 & 1.25 & 41.02 & $3,977,672$ & 2.98 & -13.52 \\
\hline A28 & 1.22 & 40.02 & $3,491,392$ & 0.76 & -17.61 & A31 & 1.20 & 37.03 & $2,634,052$ & 2.13 & -15.95 \\
\hline A29 & 1.21 & 37.03 & $2,662,570$ & 2.75 & -15.55 & & & & & & \\
\hline
\end{tabular}

Table 5. The experimental values and the predictive values of MDR ratio of these compounds.

\begin{tabular}{|c|c|c|c|c|c|c|c|c|c|c|c|c|c|}
\hline \multirow{2}{*}{ No. } & \multirow{2}{*}{$\begin{array}{c}\text { MDR } \\
\text { ratio } \\
\text { (KB-A1) }\end{array}$} & \multicolumn{5}{|c|}{ Predictive values of MDR ratio } & \multirow{2}{*}{ No. } & \multirow{2}{*}{$\begin{array}{c}\text { MDR } \\
\text { ratio } \\
\text { (KB-A1) }\end{array}$} & \multicolumn{5}{|c|}{ Predictive values of MDR ratio } \\
\hline & & Eq.1 & Eq.2 & Eq.3 & Eq.4 & Eq.5 & & & Eq.1 & Eq.2 & Eq.3 & Eq.4 & Eq.5 \\
\hline \multicolumn{14}{|c|}{ Training set } \\
\hline A1 & 171 & 114.32 & 215.61 & 200.33 & 123.15 & 180.87 & A14 & 147 & 151.94 & 151.04 & 171.02 & 173.75 & 144.79 \\
\hline A2 & 278 & 80.79 & 200.54 & 305.22 & 260.52 & 228.39 & A15 & 152 & 150.27 & 140.09 & 157.75 & 159.16 & 130.87 \\
\hline A3 & 238 & 161.08 & 71.37 & 78.37 & 79.12 & 92.55 & A16 & 209 & 115.64 & 233.15 & 217.87 & 209.32 & 197.83 \\
\hline A4 & 236 & 44.84 & 113.11 & 178.94 & 196.99 & 213.61 & A17 & 171 & 115.64 & 233.15 & 217.87 & 209.32 & 193.94 \\
\hline A5 & 160 & 150.27 & 140.09 & 157.75 & 168.14 & 148.66 & A18 & 156 & 116.97 & 252.09 & 236.91 & 229.26 & 219.10 \\
\hline A6 & 208 & 113.02 & 199.36 & 184.18 & 174.42 & 159.21 & A19 & 49 & 81.98 & 22.31 & 33.79 & 29.47 & 25.56 \\
\hline A7 & 102 & 163.01 & 77.39 & 67.24 & 80.67 & 105.63 & A20 & 214 & 198.44 & 93.91 & 119.73 & 132.46 & 165.76 \\
\hline A8 & 120 & 114.32 & 215.61 & 200.33 & 180.88 & 153.75 & A21 & 113 & 42.69 & 80.90 & 121.41 & 145.60 & 174.56 \\
\hline A9 & 75 & 237.62 & 101.82 & 179.28 & 149.94 & 146.81 & A22 & 200 & 150.27 & 140.09 & 149.67 & 160.44 & 139.02 \\
\hline A10 & 136 & 222.49 & 204.96 & 297.19 & 322.30 & 315.82 & A23 & 189 & 113.02 & 199.36 & 176.36 & 167.80 & 160.14 \\
\hline A11 & 44 & 79.86 & 58.80 & 41.66 & 49.61 & 53.08 & A24 & 142 & 92.42 & 159.30 & 116.68 & 117.52 & 112.54 \\
\hline A12 & 83 & 92.42 & 159.30 & 121.35 & 121.70 & 115.60 & A25 & 6 & 52.12 & 10.08 & 9.16 & 8.45 & 8.02 \\
\hline A13 & 272 & 53.80 & 124.41 & 185.32 & 190.50 & 197.66 & A26 & 9 & 52.12 & 10.08 & 9.53 & 8.76 & 8.16 \\
\hline \multicolumn{14}{|c|}{ Testset } \\
\hline A27 & 406 & 99.21 & 81.97 & 70.98 & 80.61 & 81.67 & A30 & 370 & 243.10 & 375.08 & 504.47 & 282.78 & 192.47 \\
\hline A28 & 68 & 163.01 & 77.39 & 67.24 & 80.67 & 106.16 & A31 & 210 & 114.32 & 215.61 & 191.82 & 183.83 & 174.21 \\
\hline A29 & 723 & 125.69 & 411.51 & 400.76 & 323.36 & 248.59 & & & & & & & \\
\hline
\end{tabular}




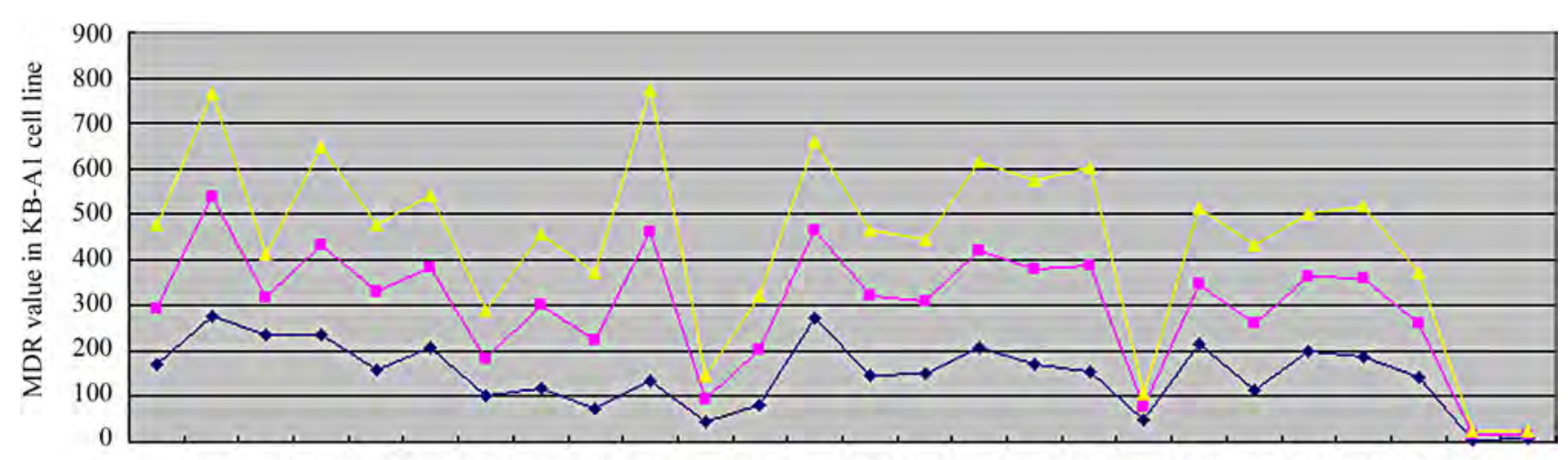

A1 A2 A3 A4 A5 A6 A7 A8 A9 A10 A11 A12 A13 A14 A15 A16 A17 A18 A19 A20 A21 A22 A23 A24 A25 A26

Compounds

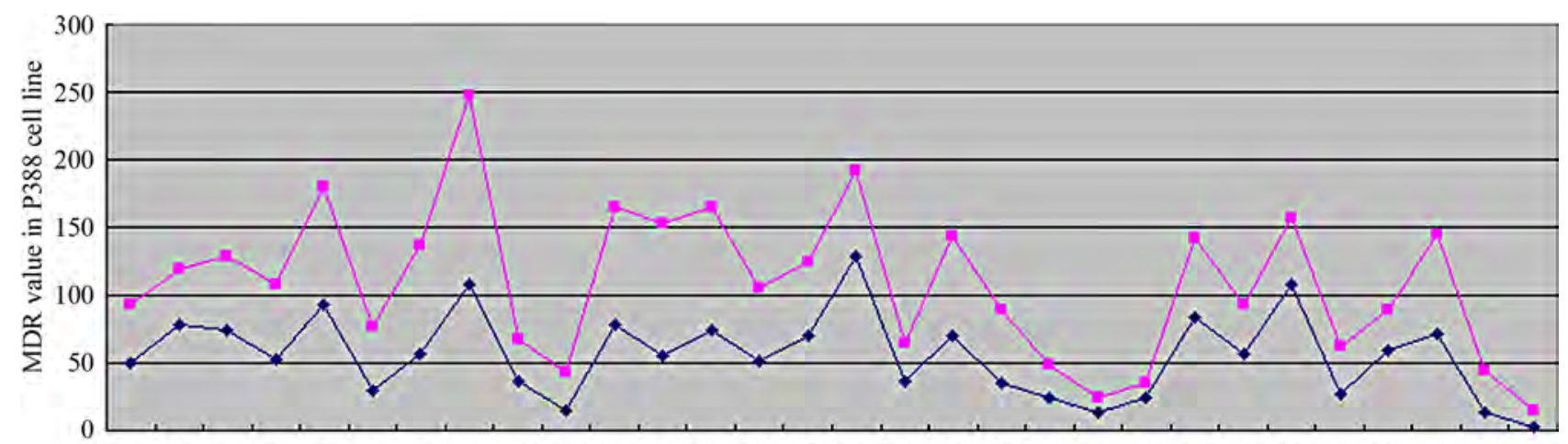

A1 A2 A3 A4 A6 A8 A9 A10A11A12A13 A14A15A16A17A18A19A20A21 A24A25A26A27A28A29A30A32 A33A34A35

Compounds

Figure 2. Comparison of the experimental MDR values with the corresponding predicted MDR values. Upper: MDR value in KB-A1/ADR cell lines (blue rhombic dots); MDR as predicted by Eq.4 MLR model (red square dots) and by Eq.5 MLR model (yellow triangle dots) for all the molecules of the training and test set. Down: MDR value in P388/VDR cell lines (blue rhombic dots); MDR as predicted by the method of PLSR (Eq.6) (red square dots) for all the molecules of the training and test set. The rhombic dots represented the experimental values (P388) and the predicted values of MDR, respectively.

Table 6. Comparison of experimental value of MDR ratio with predicted value of MDR ratio by PLSR.

\begin{tabular}{|c|c|c|c|c|c|c|c|c|c|c|c|c|c|c|c|}
\hline No. & $\begin{array}{c}\text { MDR } \\
\text { (P388) }\end{array}$ & $\begin{array}{l}\text { Pred } \\
\text { MDR }\end{array}$ & $\log P$ & MR & $\mathbf{E}_{\text {VDW }}$ & ShA & WI & No. & $\begin{array}{c}\text { MDR } \\
\text { (P388) }\end{array}$ & $\begin{array}{l}\text { Pred } \\
\text { MDR }\end{array}$ & $\log P$ & MR & $\mathbf{E}_{\text {VDW }}$ & ShA & WI \\
\hline A1 & 50 & 43.66 & 3.33 & 15.85 & 32.21 & 37.03 & 5476 & A18 & 129 & 62.87 & 2.13 & 15.90 & 27.08 & 37.03 & 5476 \\
\hline A2 & 78 & 40.71 & 2.59 & 15.10 & 21.84 & 35.08 & 4872 & A19 & 36 & 29.48 & 1.61 & 15.13 & 21.63 & 37.03 & 5585 \\
\hline A3 & 75 & 53.15 & 1.14 & 16.63 & 24.83 & 40.02 & 6522 & A20 & 70 & 73.87 & 0.76 & 17.12 & 25.52 & 41.02 & 6855 \\
\hline A4 & 53 & 55.39 & 2.21 & 13.91 & 20.16 & 32.03 & 3916 & A21 & 35 & 54.41 & 1.9 & 13.82 & 20.17 & 32.03 & 3874 \\
\hline A6 & 93 & 86.84 & 2.13 & 15.83 & 32.75 & 37.03 & 5476 & A24 & 24 & 24.57 & 2.13 & 15.39 & 23.42 & 36.03 & 4855 \\
\hline A8 & 30 & 47.64 & 2.28 & 15.85 & 25.21 & 37.03 & 5476 & A25 & 13 & 11.32 & 1.71 & 14.21 & 22.20 & 35.03 & 4487 \\
\hline A9 & 57 & 79.51 & 1.29 & 17.56 & 26.03 & 42.02 & 7353 & A26 & 24 & 11.44 & 1.71 & 14.21 & 20.92 & 35.03 & 4538 \\
\hline A10 & 108 & 138.69 & 0.99 & 17.40 & 29.44 & 41.02 & 6935 & A27 & 84 & 58.01 & 1.41 & 15.54 & 26.05 & 37.03 & 5476 \\
\hline A11 & 37 & 30.21 & 1.41 & 15.08 & 24.04 & 36.03 & 4909 & A28 & 57 & 35.88 & 0.76 & 16.66 & 23.78 & 40.02 & 6244 \\
\hline A12 & 15 & 27.61 & 2.13 & 15.39 & 23.512 & 36.03 & 4909 & A29 & 108 & 49.03 & 2.75 & 16.06 & 25.95 & 37.03 & 5476 \\
\hline A13 & 78 & 87.23 & 2.28 & 14.27 & 29.12 & 33.03 & 4216 & A30 & 27 & 35.79 & 2.98 & 17.61 & 26.49 & 41.02 & 6804 \\
\hline A14 & 56 & 96.24 & 1.48 & 16.50 & 28.19 & 39.02 & 6288 & A32 & 59 & 30.18 & 1.83 & 15.13 & 22.08 & 37.03 & 5642 \\
\hline A15 & 75 & 89.20 & 1.48 & 16.47 & 27.54 & 39.02 & 6288 & A33 & 71 & 73.84 & 0.86 & 15.79 & 27.62 & 38.03 & 5822 \\
\hline A16 & 51 & 54.90 & 2.13 & 15.88 & 25.61 & 37.03 & 5476 & A34 & 13 & 31.95 & 2.58 & 15.64 & 25.36 & 37.03 & 5476 \\
\hline A17 & 70 & 54.43 & 2.13 & 15.88 & 25.49 & 37.03 & 5476 & A35 & 3 & 12.22 & 1.71 & 14.21 & 20.40 & 35.03 & 4589 \\
\hline
\end{tabular}


the result of predicted value was in Table 5.

$$
\begin{aligned}
\operatorname{LogMDR} & =-6.537+7.162 \operatorname{LogMR} \\
N & =27 ; R=0.445 ; \quad F=6.187 \\
\operatorname{LogMDR} & =-37.830+48.862 \operatorname{LogMR}-0.499 \mathrm{ShA} \\
N & =27 ; R=0.889 ; F=45.415
\end{aligned}
$$

$\operatorname{LogMDR}=-35.816+52.416 \operatorname{LogMR}-0.717 \mathrm{ShA}+$ $6.612 \times 10^{-7} \mathrm{BI}$

$$
N=27 ; R=0.919 ; F=41.442
$$

LogMDR $=-38.791+56.923 \operatorname{LogMR}-0.769 \mathrm{ShA}+$ $5.897 \times 10^{-7} \mathrm{BI}-0.159 \log \mathrm{P}$

$$
N=27 ; R=0.927 ; F=33.504
$$

$\operatorname{LogMDE}=-42.192+61.818 \operatorname{LogMR}-0.801 \mathrm{ShA}+$ $4.791 \times 10^{-7} \mathrm{BI}-0.369 \log \mathrm{P}+3.595 \times 10^{-2} \mathrm{E}_{\text {hyd }}$

$$
N=27 ; R=0.936 ; F=29.749
$$

LogMDR $=7.611+3.138 \times 10^{-2} \log \mathrm{P}-0.245 \mathrm{MR}+$ $0.495 \mathrm{EVDW}_{\mathrm{VDW}}-0.509 \mathrm{ShA}+8.802 \times 10^{-4} \mathrm{WI}$

$$
N=30 ; Q^{2}=0.4650
$$

\subsection{QSAR Analysis Based on Ka of ATPase in CCRF ADR5000 Cell Lines}

Meanwhile, took Ka of ATPase of compounds in CCRF ADR5000 cell lines as dependent variable. Some QSAR models of a training set of 16 compounds were built using MLD method (Eqs.7-11) and PLSR method (Eq.12) (see Figure 3). All the molecular descriptors were listed in Table 7. A test set of 2 compounds was evaluated using the models as part of a validation process. Table 8 displays the comparison of the experiment Ka and prediction Ka values of ATPase.

$$
\begin{aligned}
& \operatorname{LogKa}=2.424-0.484 \log \mathrm{P} \\
& N=16 ; R=0.860 ; F=39.748 \\
& \operatorname{LogKa}=3.612-0.285 \log \mathrm{P}-0.0732 \mathrm{Sh} \mathrm{A} \\
& N=16 ; R=0.900 ; F=27.676 \\
& \operatorname{LogKa}=2.573-0.480 \log \mathrm{P}-0.285 \mathrm{ShA}+0.651 \mathrm{MR} \\
& N=16 ; R=0.914 ; F=20.251 \\
& \operatorname{LogKa}=7.313-0.752 \log \mathrm{P}-0.647 \mathrm{Sh} \mathrm{A}+1.642 \\
& \mathrm{MR}+0.605 \mathrm{E}_{\text {Номо }} \\
& \mathrm{N}=16 ; \mathrm{R}=0.928 ; \mathrm{F}=17.111 \\
& \operatorname{LogKa}=10.021-0.875 \log \mathrm{P}-1.044 \mathrm{ShA}+2.263 \\
& \mathrm{MR}+0.673 \mathrm{E}_{\text {Номо }}+6.734 \times 10^{-4} \mathrm{WI} \\
& N=16 ; R=0.945 ; F=16.832 \\
& \operatorname{LogKa}=3.662-0.279 \log \mathrm{P}-4.71 \times 10^{-3} \mathrm{MW}+ \\
& 1.223 \times 10^{-2} \mathrm{E}_{\text {номо }} \\
& N=18, Q^{2}=0.7100
\end{aligned}
$$

\subsection{QSAR Analysis Based on BBB Partitioning of Organic Compounds}

On the other hand, 37 organic compounds of training set and 8 compounds of test set were built and minimized, dissolved in liquid, and optimized by Monte Carlo method. Molecular modeling of the compound-membrane-water complex model revealed that the energy of an organic compound inserted at the middle position in the DMPC model with a layer of water was lower than that of the other two positions. Molecular descriptors of compounds in a training set and a test set are listed in Table 9. Six QSAR equations were constructed based on Table 9 and were listed as follows.

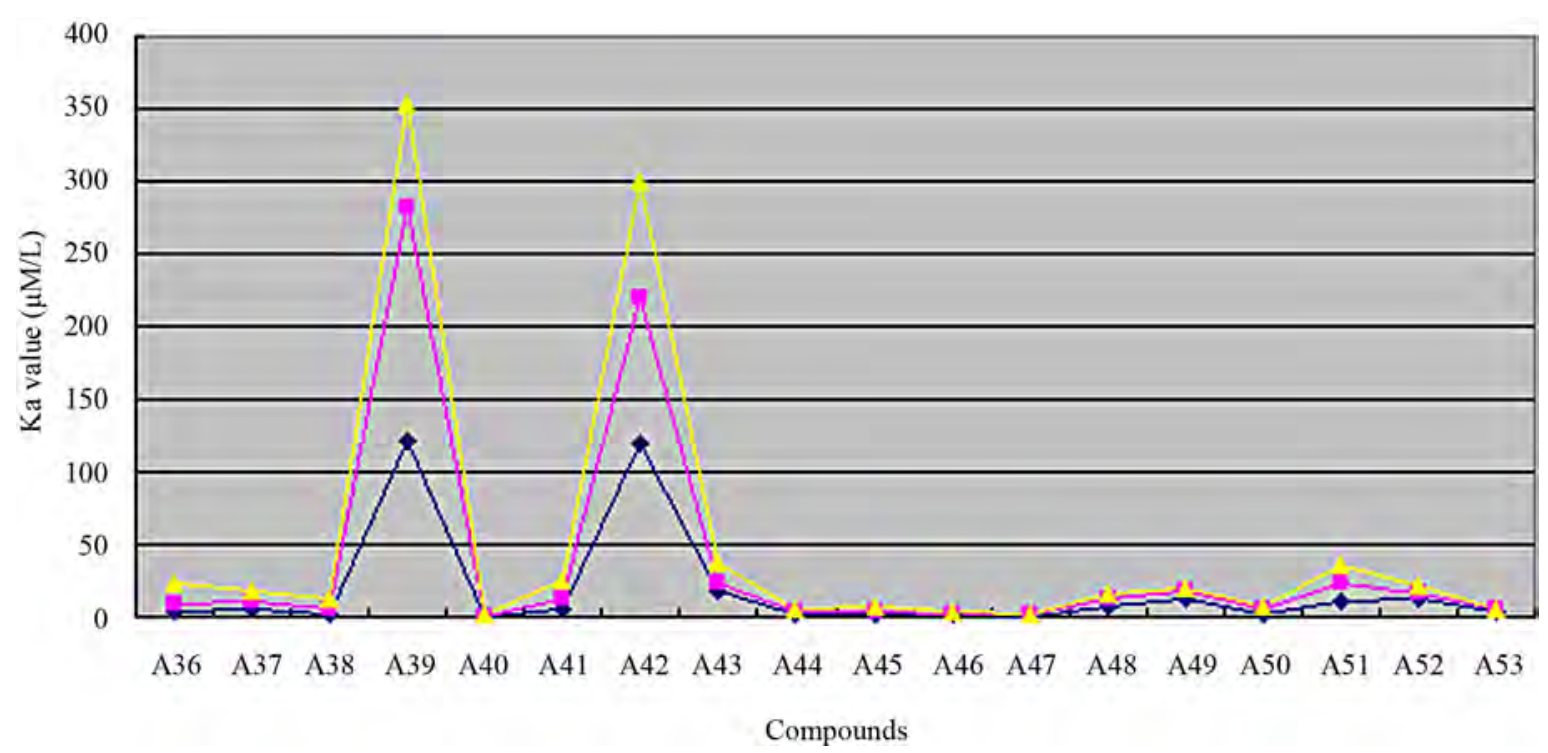

Figure 3. Comparison of the experimental Ka value (blue rhombic dots) with the corresponding predicted Ka as predicted by Eq.11 MLR model (red square dats) and by Eq.12 PLSR model (yellow triangle dots) for all the molecules of the training and test. 
Table 7. The molecular descriptors of some compounds related to ATPase in the training/test sets.

\begin{tabular}{cccccccccccccc}
\hline No. & LogP & ShA & MR & E номо $_{\text {(eV) }}$ & WI & MW & No. & LogP & ShA & MR & E $_{\text {номо }}(\mathbf{e V})$ & WI & MW \\
\hline A36 & 3.39 & 21.04 & 9.254 & -9.14 & 1366 & 312.41 & $\mathbf{A 4 5}$ & 4.3 & 26.04 & 11.42 & -9.17 & 2345 & 383.53 \\
A37 & 3.62 & 24.04 & 10.55 & -9.20 & 1949 & 355.48 & $\mathbf{A 4 6}$ & 4.93 & 32.03 & 13.27 & -8.24 & 4689 & 462.57 \\
A38 & 3.67 & 25.04 & 10.84 & -9.16 & 2172 & 367.49 & $\mathbf{A 4 7}$ & 5.2 & 32.03 & 13.38 & -8.19 & 4329 & 464.58 \\
A39 & 1.42 & 18.05 & 7.86 & -9.12 & 920 & 277.37 & $\mathbf{A 4 8}$ & 4.25 & 26.04 & 11.45 & -9.24 & 2607 & 383.53 \\
A40 & 4.93 & 32.03 & 13.27 & -8.16 & 4329 & 462.57 & $\mathbf{A 4 9}$ & 4.52 & 26.04 & 11.59 & -8.94 & 2367 & 385.55 \\
A41 & 2.67 & 25.04 & 10.29 & -8.15 & 2244 & 372.44 & $\mathbf{A 5 0}$ & 4.88 & 27.03 & 12.06 & -8.94 & 2550 & 399.58 \\
A42 & 0.94 & 19.05 & 8.01 & -9.15 & 1050 & 293.37 & $\mathbf{A 5 1}$ & 2.38 & 26.04 & 10.99 & -9.09 & 2400 & 383.49 \\
A43 & 2.54 & 25.04 & 10.52 & -9.20 & 2172 & 369.46 & $\mathbf{A 5 2}$ & 3.94 & 25.04 & 10.95 & -9.05 & 2172 & 369.51 \\
A44 & 3.98 & 32.03 & 13.50 & -9.16 & 4227 & 459.59 & $\mathbf{A 5 3}$ & 4.93 & 32.03 & 13.27 & -8.19 & 4509 & 462.57 \\
\hline
\end{tabular}

Table 8. Comparison the experimental values with the predictive values of Ka of these compounds.

\begin{tabular}{|c|c|c|c|c|c|c|c|c|c|c|c|c|c|c|c|}
\hline \multirow{2}{*}{ No. } & \multirow{2}{*}{$\begin{array}{c}\text { Ka } \\
(\mu \mathrm{M} / \mathrm{L})\end{array}$} & \multicolumn{6}{|c|}{ Predictive values of Ka } & \multirow{2}{*}{ No. } & \multirow{2}{*}{$\underset{(\mu \mathrm{Ma} / \mathrm{L})}{\mathbf{K a}}$} & \multicolumn{6}{|c|}{ Predictive values of Ka } \\
\hline & & Eq.7 & Eq.8 & Eq.9 & Eq.10 & Eq.11 & Eq.12 & & & Eq.7 & Eq.8 & Eq.9 & Eq.10 & Eq.11 & Eq.12 \\
\hline A36 & 3.34 & 6.07 & 12.75 & 9.37 & 6.43 & 6.14 & 13.57 & A45 & 1.53 & 2.20 & 3.02 & 3.32 & 2.69 & 2.08 & 3.50 \\
\hline A37 & 5.30 & 4.70 & 6.62 & 7.10 & 6.19 & 5.60 & 7.33 & A46 & 1.47 & 1.09 & 0.73 & 0.52 & 0.48 & 0.81 & 1.02 \\
\hline A38 & 2.59 & 4.44 & 5.41 & 5.36 & 3.98 & 3.06 & 6.24 & A47 & 0.55 & 0.81 & 0.61 & 0.46 & 0.50 & 0.53 & 0.84 \\
\hline A39 & 122 & 54.54 & 76.92 & 73.09 & 90.64 & 160.46 & 70.37 & A48 & 7.64 & 2.33 & 3.13 & 3.83 & 3.33 & 4.22 & 3.60 \\
\hline A40 & 0.36 & 1.09 & 0.73 & 0.52 & 0.53 & 0.51 & 1.02 & A49 & 12.20 & 1.72 & 2.62 & 3.39 & 4.98 & 5.00 & 2.99 \\
\hline A41 & 6.13 & 13.54 & 10.43 & 7.17 & 11.79 & 7.23 & 11.56 & A50 & 2.26 & 1.15 & 1.75 & 2.37 & 3.50 & 3.28 & 2.04 \\
\hline A42 & 120.00 & 93.12 & 89.09 & 81.21 & 80.47 & 99.37 & 80.44 & A51 & 10.50 & 18.71 & 10.66 & 14.57 & 16.6 & 13.20 & 12.02 \\
\hline A43 & 18.50 & 15.65 & 11.36 & 11.73 & 8.26 & 5.56 & 12.59 & A52 & 12.80 & 3.29 & 4.53 & 4.74 & 4.57 & 3.91 & 5.15 \\
\hline A44 & 1.01 & 3.15 & 1.36 & 2.10 & 1.66 & 2.13 & 1.88 & A53 & 4.15 & 1.09 & 0.73 & 0.52 & 0.51 & 0.65 & 1.02 \\
\hline
\end{tabular}

Table 9. The molecular descriptors of the compounds related to BBB in the training/test sets.

\begin{tabular}{|c|c|c|c|c|c|c|c|c|}
\hline No & $\operatorname{PSA}\left(\AA^{2}\right)$ & $C \log P$ & BI ( $(\AA)$ & $\mathbf{E}_{\text {stretch }}(\mathrm{Kcal} / \mathbf{m o l})$ & $E_{\text {total }}{ }^{a}(\mathrm{Kcal} / \mathbf{m o l})$ & $\mathrm{E}_{\text {torsion }}{ }^{\mathrm{a}}(\mathrm{Kcal} / \mathrm{mol})$ & $\Delta \mathrm{E}_{\text {total }}^{\mathrm{b}}(\mathrm{Kcal} / \mathrm{mol})$ & $\Delta \mathrm{E}_{\text {torsion }}^{\mathrm{b}}(\mathrm{Kcal} / \mathrm{mol})$ \\
\hline \multicolumn{9}{|c|}{ Training set } \\
\hline B1 & 78.90 & 1.20 & 12378 & -1.35503 & -298.2972 & -1713.1146 & 42.46 & 11.30 \\
\hline B2 & 94.00 & 1.99 & 1101758 & -0.15595 & -406.0803 & -1789.8084 & -65.32 & -65.39 \\
\hline B3 & 73.00 & 3.80 & 1738650 & -1.48472 & -256.3021 & -1703.1425 & 84.46 & 21.27 \\
\hline B4 & 87.00 & 1.63 & 1346396 & -1.39112 & -302.7543 & -1841.5635 & 38.00 & -117.15 \\
\hline B5 & 39.00 & 1.02 & 41807 & 0.58131 & -226.3773 & -1734.7452 & 114.38 & -10.33 \\
\hline B6 & 26.80 & 3.23 & 305770 & -0.09264 & -228.2923 & -1679.4604 & 112.47 & 44.96 \\
\hline B7 & 88.80 & 1.01 & 58510 & 0.71038 & -279.0781 & -1671.3414 & 61.68 & 53.07 \\
\hline B8 & 76.60 & 2.80 & 62216 & -0.38334 & -309.2981 & -1654.6730 & 31.46 & 69.74 \\
\hline B9 & 104.40 & 1.77 & 83798 & -0.35599 & -313.4237 & -1639.9898 & 27.34 & 84.43 \\
\hline B10 & 108.80 & 2.00 & 193593 & -0.52172 & -548.5593 & -1640.9214 & -207.80 & 83.49 \\
\hline B11 & 47.90 & 2.51 & 352512 & -0.09496 & -312.1226 & -1656.7465 & 28.64 & 67.67 \\
\hline B12 & 45.20 & 4.27 & 779210 & 0.00479 & -163.8011 & -1716.3101 & 176.96 & 8.11 \\
\hline B13 & 38.50 & 2.61 & 158640 & -0.09491 & -170.3338 & -1716.7159 & 170.43 & 7.70 \\
\hline B14 & 40.00 & 4.28 & 431722 & -1.30506 & -247.0951 & -1748.0241 & 93.66 & -23.61 \\
\hline B15 & 39.20 & 5.88 & 766256 & 0.09911 & -289.2825 & -1735.4004 & 51.48 & -10.98 \\
\hline B16 & 54.90 & 5.14 & 766256 & -0.14215 & -181.0636 & -1743.6068 & 159.70 & -19.19 \\
\hline B17 & 18.80 & 0.62 & 20863 & 0.18071 & -331.7044 & -1695.6999 & 9.05 & 28.72 \\
\hline
\end{tabular}




\begin{tabular}{|c|c|c|c|c|c|c|c|c|}
\hline \multicolumn{9}{|c|}{ Continued } \\
\hline B18 & 46.70 & 0.27 & 20264 & -1.36843 & -209.4697 & -1644.6752 & 131.29 & 79.74 \\
\hline B19 & 44.10 & 2.80 & 190375 & -2.97778 & -311.9182 & -1713.8942 & 28.84 & 10.52 \\
\hline B20 & 5.40 & 4.85 & 210631 & -0.06079 & -235.7250 & -1704.3399 & 105.03 & 20.08 \\
\hline B21 & 0.00 & -0.47 & 4 & 0.00000 & -407.3194 & -1729.3793 & -66.56 & -4.96 \\
\hline B22 & 0.00 & 2.14 & 972 & -0.00009 & -239.8807 & -1675.1827 & 100.88 & 49.23 \\
\hline B23 & 23.40 & 0.07 & 213 & 0.00000 & -160.1278 & -1672.3898 & 180.63 & 52.03 \\
\hline B24 & 22.60 & 0.69 & 712 & 0.00000 & -319.0674 & -1742.6968 & 21.69 & -18.28 \\
\hline B25 & 0.00 & 3.74 & 1899 & 0.00067 & -282.3721 & -1751.6193 & 58.39 & -27.20 \\
\hline B26 & 0.00 & 3.61 & 1661 & 0.00000 & -285.7132 & -1731.9518 & 55.05 & -7.54 \\
\hline B27 & 0.00 & 1.43 & 1661 & -0.00008 & -238.7249 & -1731.3090 & 102.03 & -6.89 \\
\hline B28 & 0.00 & 2.48 & 633 & 0.00003 & -291.5583 & -1725.7370 & 49.20 & -1.32 \\
\hline B29 & 11.60 & 2.46 & 21380 & -0.00005 & -418.0323 & -1682.7138 & -77.27 & 41.70 \\
\hline B30 & 24.40 & -0.24 & 47 & 0.00000 & -329.3150 & -1704.6187 & 11.44 & 19.80 \\
\hline B31 & 10.70 & 1.27 & 7864 & -0.00002 & -253.3453 & -1747.7044 & 87.41 & -23.29 \\
\hline B32 & 0.00 & 2.37 & 7322 & -0.00003 & -268.8335 & -1714.2486 & 71.93 & 10.17 \\
\hline B33 & 0.00 & 3.31 & 931 & 0.02567 & -353.8395 & -1739.7672 & -13.08 & -15.35 \\
\hline B34 & 24.40 & -0.24 & 47 & 0.00000 & -187.4520 & -1720.5500 & 153.31 & 3.87 \\
\hline B35 & 0.00 & 1.93 & 7322 & -0.00003 & -177.4875 & -1728.8621 & 163.27 & -4.45 \\
\hline B36 & 0.00 & 2.64 & 2050 & -0.02344 & -220.3940 & -1681.1548 & 120.36 & 43.26 \\
\hline B37 & 0.00 & 2.63 & 712 & -0.00002 & -231.5752 & -1722.2582 & 109.18 & 2.16 \\
\hline \multicolumn{9}{|c|}{ Test set } \\
\hline $\mathbf{T 1}$ & 22.70 & 0.321 & 712 & 0.00000 & -274.7201 & -1713.7409 & 66.04 & 10.68 \\
\hline $\mathbf{T} 2$ & 0.00 & 3.738 & 1838 & 0.00000 & -225.6308 & -1716.6234 & 115.13 & 7.79 \\
\hline T3 & 0.00 & 4.267 & 4150 & 0.00000 & -331.3754 & -1700.6397 & 9.38 & 23.78 \\
\hline T4 & 11.30 & 0.870 & 791 & 0.00000 & -181.5954 & -1700.8447 & 159.16 & 23.57 \\
\hline T5 & 0.00 & 4.397 & 4650 & 0.00000 & -404.2903 & -1741.2420 & -63.53 & -16.83 \\
\hline T6 & 0.00 & 1.103 & 0 & 0.00000 & -282.9386 & -1746.1889 & 57.82 & -21.77 \\
\hline T7 & 0.00 & 3.339 & 791 & 0.00063 & -271.9174 & -1681.9440 & 68.84 & 42.47 \\
\hline T8 & 22.70 & -0.208 & 213 & 0.00000 & -364.8884 & -1695.3605 & -24.13 & 29.06 \\
\hline
\end{tabular}

Note: ${ }^{\mathbf{a}} \mathrm{E}_{\text {total }}$ and $\mathrm{E}_{\text {torsion }}$ mean the total energy and the torsion energy of the compound-DMPC-water complex; ${ }^{\mathbf{b}} \Delta \mathrm{E}_{\text {total }}$ and $\Delta \mathrm{E}_{\text {torsion }}$ are the residues between the compound-DMPC-water complex and the DMPC-water complex.

$$
\begin{gathered}
\log \mathrm{BB}=0.552-1.73 \times 10^{-2} \mathrm{PSA} \\
n=37 R=0.835 \mathrm{~S}=0.398 \\
\log \mathrm{BB}=0.229-1.70 \times 10^{-2} \mathrm{PSA}+0.131 \mathrm{Cl} \log \mathrm{P} \\
\quad n=37 R=0.878 \mathrm{~S}=0.352 \\
\log \mathrm{BB}=4.965 \times 10^{-2}-1.28 \times 10^{-2} \mathrm{PSA}+0.211 \\
\mathrm{Clog}-6.40 \times 10^{-7} \mathrm{BI} \\
n=37 R=0.924 \mathrm{~S}=0.285 \\
\operatorname{LogBB}=6.262 \times 10^{-2}-1.36 \times 10^{-2} \mathrm{PSA}+0.205 \\
\mathrm{ClogP}-7.11 \times 10^{-7} \mathrm{BI}-0.185 \mathrm{E}_{\text {stretch }} \\
n=37 R=0.938 \mathrm{~S}=0.264 \\
\operatorname{LogBB}=6.580 \times 10^{-2}-1.21 \times 10^{-2} \mathrm{PSA}+0.206 \\
\mathrm{Clog}-7.77 \times 10^{-7} \mathrm{BI}-0.197 \mathrm{E}_{\text {stretch }}+1.330 \times 10^{-3}
\end{gathered}
$$
$\Delta \mathrm{E}_{\text {total }}$

$$
n=37 R=0.947 S=0.248
$$

$\log B B=8.730 \times 10^{-2}-1.04 \times 10^{-2} \mathrm{PSA}+0.222$ $\mathrm{C} \log \mathrm{P}-9.60 \times 10^{-7} \mathrm{BI}-0.183 \mathrm{E}_{\text {stretch }}+1.364 \times 10^{-3}$ $\Delta \mathrm{E}_{\text {total }}-2.68 \times 10^{-3} \Delta \mathrm{E}_{\text {torsion }}$

$$
n=37 R=0.955 S=0.232
$$

Here, $n$ means the number of compounds in a training set, $R$ means the correlative coefficient, and $S$ means the standard residual error. $\operatorname{LogBB}=\log \left(\mathrm{C}_{\text {brain }} / \mathrm{C}_{\text {blood }}\right)$. PSA means the total polar surface area of a molecule. CLogP and $\mathrm{BI}$ display calculated $\log \mathrm{P}$ and connective index of molecular average total distance (relative covalent radius), respectively. They come from CS calculation. $\Delta \mathrm{E}_{\text {total }}$ and $\Delta \mathrm{E}_{\text {torsion }}$ are related to interaction between a compound and the membrane-water model. The total energy 
and the torsion energy of the membrane-water complex are -340.7589 and $-1724.4164(\mathrm{Kcal} / \mathrm{mol})$, respectively. $\Delta \mathrm{E}_{\text {total }}$ is the change in the total potential energy of the solute-membrane-water complex comparing with that of the membrane-water model and so is $\Delta \mathrm{E}_{\text {torsion. }}$.

With the increase of the independent variable, the relativity of QSAR model was also improved and its predictive ability was enhanced. The most significant Eq.18 displayed that the capability of a compound through $\mathrm{BBB}$ was directly proportional to $\mathrm{Clog} \mathrm{P}$ and $\Delta \mathrm{E}_{\text {total }}$, but inversely proportional to PSA, BI, $\mathrm{E}_{\text {stretch, }}$ and $\Delta \mathrm{E}_{\text {torsion }}$. Figure 4 showed the comparison of the experimental $\log \mathrm{BB}$ with the corresponding predicted $\log \mathrm{BB}$ of the molecules in the training set based on Eqs.17 and 18 models (see Table 10). Compound B18 was predicted with a higher $\log B \mathrm{~B}$ than observed, supported by the result of Iyer et al. [35].

The test set of 8 compounds to span almost the entire range in BBB partitioning was selected for validation of the QSAR models mentioned above. The observed and predicted $\log B \mathrm{~B}$ values for this test set were given in Table 10 and plotted in Figure 4 (right). It seemed to suggest that Eqs.17 and 18 models could predict $\operatorname{logBB}$ for other compounds in drug design.

\section{DISCUSSION}

Some predictive models of MDR, Ka and BBB partitioning of organic compounds were built by simulating the interaction between modulators or drugs and P-gp and/or the interreaction of the organic compound with the phospholipide-rich regions of cellular membranes. We have constructed theoretical models of the interaction between organic compounds and P-gp and compounds with the affinity for and simulation of the P-gp ATPase. On one hand, the interaction between compounds and P-gp (P-gp binding or MDR-reversal activity of compounds) is found to depend on $\log P$, $\log M R$, and ShA of compounds it transports, which proportional to Log MR whereas inversely proportional to LogP and ShA (see Eqs.1-5). Moreover, modulators or drugs interacting with P-gp and thus reducing the efflux of the cytotoxic compounds would increase the apparent toxicity of the cytotoxic compounds, which might account for more than one mechanism of action in the resistant cells used. There were many uncertainty factors in the MDR ratio assay method which was convinced by our linear

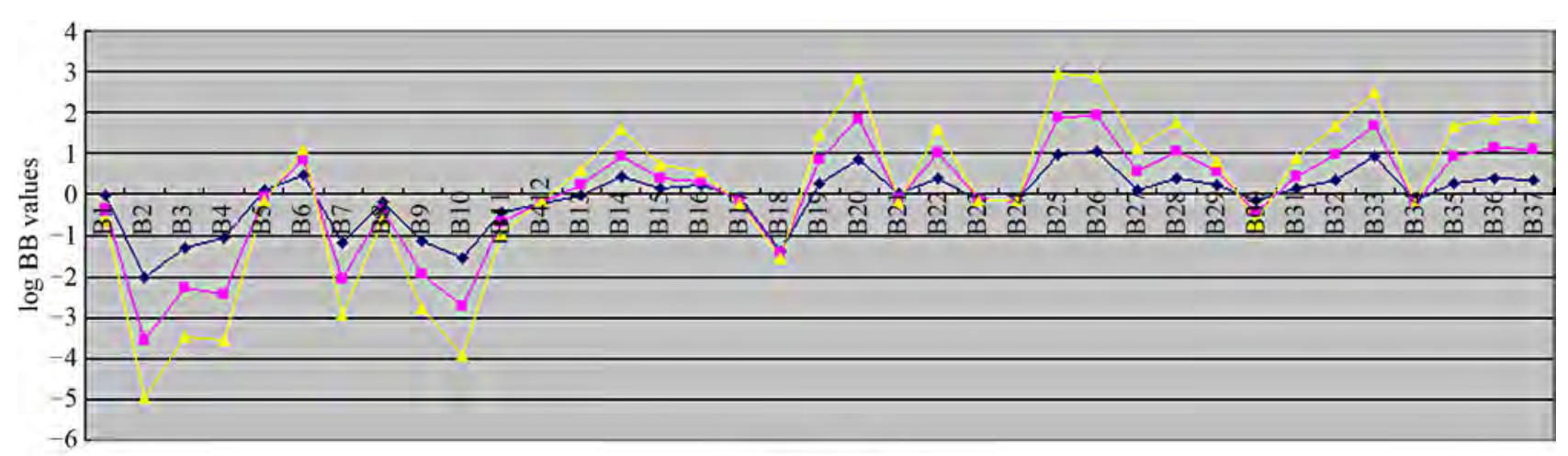

Compounds

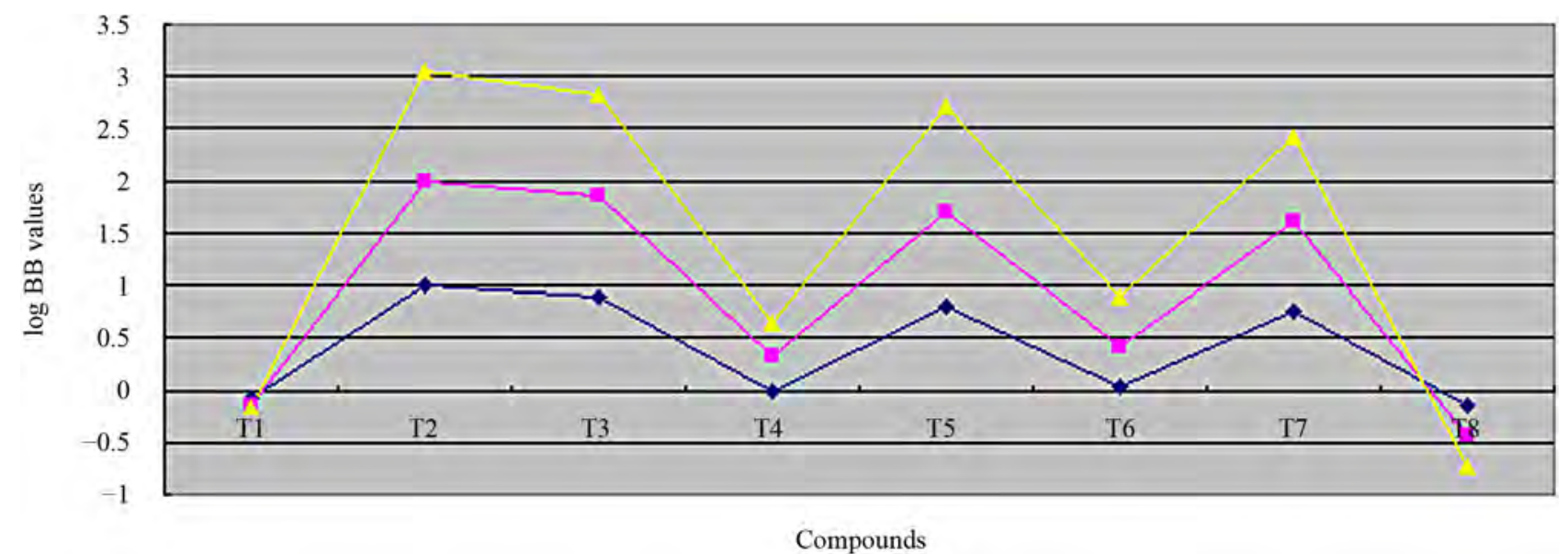

Figure 4. Comparison of the experimental logBB values (blue rhombic dots) for all the molecules of the training sets (upper) or the test set (down) to the corresponding predicted $\operatorname{logBB}$ as predicted by Eq.17 MI-QSAR model (red square dots) and by Eq.18 MI-QSAR model (yellow triangle dots). 


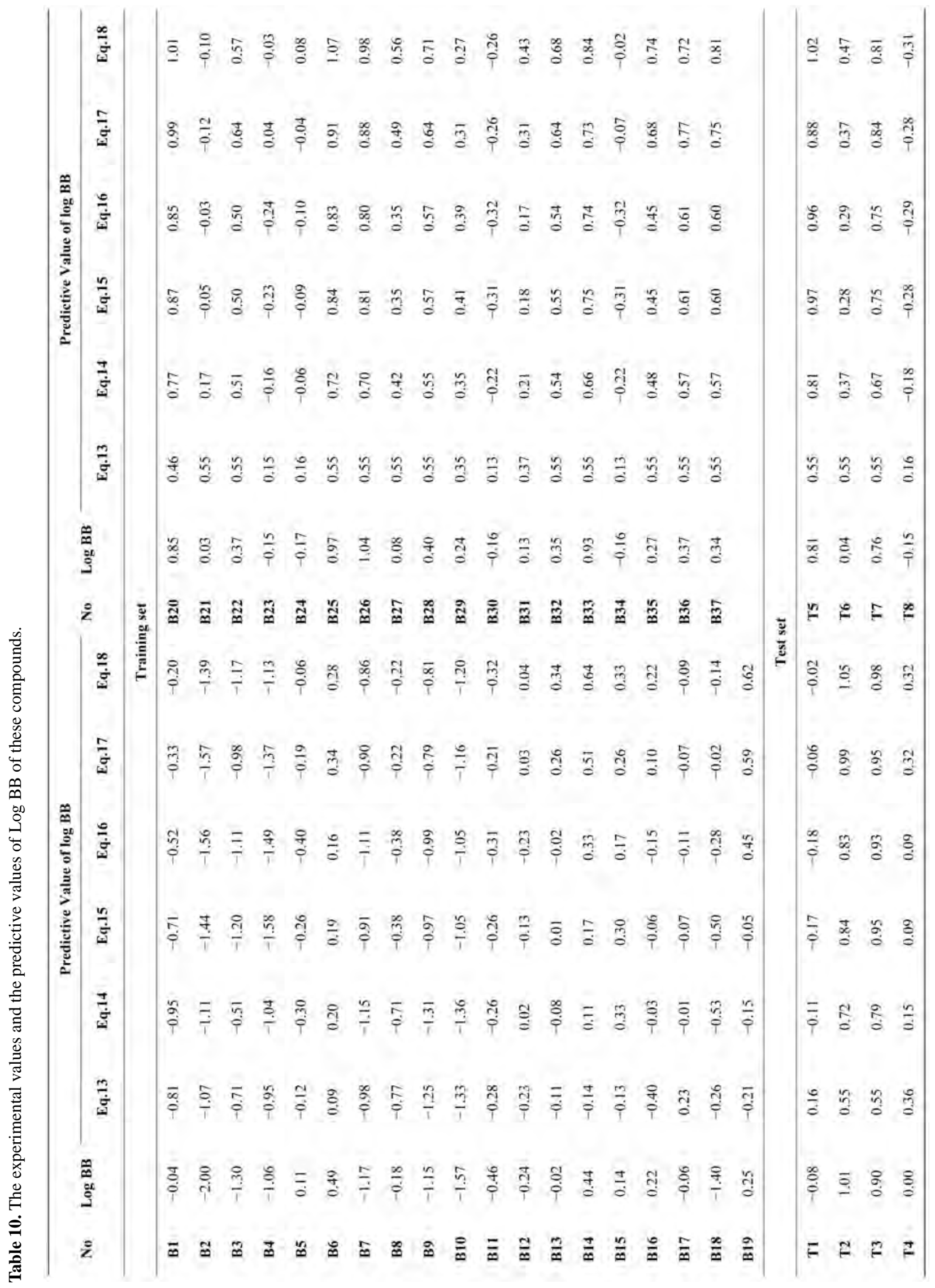


regression models. Our research results using two different statistic methods, MLR and PLSR, have revealed that the QSAR equation was also improved and the predictive ability of the models was enhanced with the increase of the variable. Eq.5 was built on KB-A1 cell line with a cytotoxic compound of $2.5 \mu \mathrm{M}$ ADR while Eq.6 was based on P388/VDR-20 cell line with $1.5 \mu \mathrm{M}$ VCR. Here, most of the models gave satisfactory cross-validated $Q^{2}$ above 0.500 , conventional $R$ above 0.800 and less $\mathrm{SE}$ values, indicating their proper predictive ability. Significant differences between values were examined using two-tailed paired T test provided by SPSS. All the results were considered not significant if $\mathrm{P}<0.05$. Eq.5 model was the most significant and indicated that the potential of P-gp modulators interacted with P-gp depended upon MR, BI, E $\mathrm{h}_{\mathrm{hyd}}$, ShA, and LogP. The former three displayed positive contributions to the MDR activity of P-gp, suggesting that the MDR activity increased accordingly with the increase of MR. The latter two displayed negative contribution to the MDR activity of P-gp.

On the other hand, our built models for Ka of ATPase based on the analogies of purine and propafenone analogs suggested that the enzyme hydrolysis of these compounds largely depended on LogP, MR, ShA, MW and $\mathrm{E}_{\mathrm{HOMO}}$, especially positive related to MR but negative to LogP and ShA (see Eqs.7 to 11). Both models, Eq.11 by MLR and Eq.12 by PLSR, pointed out that $\mathrm{E}_{\text {номо, posi- }}$ tive related with the activity of P-gp ATPase, was an important parameter for the compound stimulated ATPase activity with high affinity, whereas another LogP was negative related with the activity of P-gp ATPase. Figure 3 showed that molecular A39 and A42 with higher Ka value of ATPase were depart from other compounds. This may be because they have lower lipophilicity, which is supported by the research results of Diethart Schmid et al. [31]. The results above showed that the P-gp binding capacity of these compounds shares common characteristics with their ATPase hydrolysis, namely their hydrophobic parameters (such as $\log \mathrm{P}$ ) and steric parameters (e.g. MW, ShA, and MR).

In another aspect, our MI-QSAR models indicated that the distribution of organic molecules through BBB was not only influenced by organic solutes themselves, but also related to the properties of the solute-membranewater complex, namely interactions of the molecule with the phospholipide-rich regions of cellular membranes. The QSAR model, especially Eq.18 most significant, revealed that the capability of BBB partitioning of an organic compound focused on six significant features. Obviously, two descriptors, $C \log \mathrm{P}$ and $\Delta \mathrm{E}_{\text {total }}$, had positive regression coefficients and the other four descriptors, PSA, BI, $E_{\text {stretch, }}$ and $\Delta E_{\text {torsion, }}$, had negative regression coefficients. Moreover, PSA descriptor was found as a dominant descriptor in these QSAR models, which was related to the aqueous solubility of the solute compound along with a direct lipophilicity descriptor. When the value of PSA of a molecule lessened within the range from 0 to $108.80 \AA^{2}$, its value of $\operatorname{LogBB}$ would increase. This was consistent with the experimental results that the more polarity it possessed, the more difficultly a molecule entered the hydrophobic environment of BBB [38]. $\mathrm{BI}$ as the connective index of molecular average total distance pertained to the volume parameter. Our research result showed that a molecule more and more difficultly acrossed through BBB by diffusion with the addition of its bulk. However, the value of $\operatorname{LogBB}$ of a molecule increased with the increase of ClogP. It meaned that the hydrophobic molecule could pass through BBB more easily than the hydrophilic molecule does. The presence of $E_{\text {stretch }}$ descriptor suggested that with the decrease of the stretch-bend energy of a molecule, its value of LogBB increased. Two of the descriptors, $\Delta \mathrm{E}_{\text {total }}$ and $\Delta \mathrm{E}_{\text {torsion, }}$, found in the $\operatorname{logBB}$ QSAR models (Eqs.17 and 18), reflected the behavior of the solutes in the membrane and the entire membrane-solute complex. Along with the meaning mentioned, $\Delta \mathrm{E}_{\text {total }}$ was equivalent to the change in the average total potential energy between the ternary complex of solute-membrane-water and the binary complex of membrane-water. Similarly, $\Delta \mathrm{E}_{\text {torsion }}$ was the difference between the dihedral torsion energy of the ternary complex and that of the binary complex. Here, the more the change value of $\Delta \mathrm{E}_{\text {total }}$ was, the more its value of $\operatorname{LogBB}$ increased. This may be because small molecules across BBB membrane could lead to the change of the complex structure. The more changeability of the structure resulted in greater change of the total potential energy, while the addition of the energy change could be the important cause of the increase of the capability of a small molecule through BBB. On the contrary, the less the difference of the torsion energy was, the larger its LogBB value was. It displayed that a small molecule tight combined with the membrane-water complex could lead to the increase of its $\operatorname{LogBB}$. Moreover, the relationship would suggest that the solute became more flexible within the membrane-water complex, which would possess the greater $\log B B$ value, in agreement with the research results of Iyer $\mathrm{M}$ et al. [35]. Furthermore, BBB partitioning was mainly found to depend upon two parameters, namely PSA and ClogP, where the ability of organic molecules permeating across BBB was directly proportional to LogP but inversely proportional to PSA (see Eqs.13-18), which was consistent with the research results of Chen and co-worker [2], namely the increasing PSA decreased LogBB rapidly while LogP was positively related to $\operatorname{LogBB}$. It indicated that molecules with higher lipophilic would be partitioned into the lipid bilayer more easily with more chances to penetrate BBB, sup- 
ported by the research result of Wang et al., namely a large number of structurally and functionally diverse compounds as substrates or modulators of P-gp mostly sharing common structural features, such as aromatic ring structures and high lipophilicity [19]. PSA of CNS active drug should be lower than $90 \AA^{2}$ [2], while the penetration through the BBB is optimal for LogP value in the range 1.5 - 2.7 (Norinder \& Haeberlein, 2002).

In addition, several non-MI-QSAR computational models to describe and predict BBB partitioning have been reported that includes other descriptors besides PSA and ClogP [39]. An alternative, complementary approach to BBB partitioning prediction uses MI-QSAR analysis developed by Iyer $\mathrm{M}$ et al. [35]. Their research results showed that BBB partitioning of an organic compound depended upon PSA, CLogP, and the conformational flexibility of the compounds as well as the strength of their "binding" to the model biologic membrane. The MI-QSAR models indicated that BBB partitioning process could be reliably described for structurally diverse molecules and provided interactions of the molecule with the phospholipide-rich regions of cellular membranes. An extension of these approaches that combined QSAR with solute-membrane-water complex had been developed by us, which was addition of a layer of water on the hydrophilic side of DMPC monolayer membrane in order to simulate the truth BBB environment. Our results revealed that the distribution of organic molecules through BBB was not only influenced by the properties of organic solutes, but also related to the property of the solute-membrane-water complex. The former involved the polarity, hydrophobic, size, and conformational freedom degree of organic molecules, while the latter dealt with the strength of an organic molecule combined with BBB membrane and the structural changeability of a solutemembrane-water complex. Furthermore, the capability of a small molecule across BBB was mainly related to four physicochemical factors, which depended on the relative polarity of a small molecule (namely PSA and ClogP), the molecular volume (i.e. BI), the strength of a small molecule combined with DMPC-water model (viz. $\Delta \mathrm{E}_{\text {torsion }}$ ), and the changeability of the structure of a solute-membrane-water complex (scilicent $\Delta \mathrm{E}_{\text {total }}$ ). The QSAR model showed that the less polarity and more hydrophobic molecules relatively easily passed through BBB and entered brain to cure. The reason for the change of the total energy was that small molecules across BBB membrane caused the structural change of the solute-membrane-water complex. The more the changeability of the complex structure was, the more the change value of its total energy was, and the more easily a small molecule penetrated BBB.

In particular, cerebral clearance of $\mathrm{A} \beta$ was considered to occur via elimination across BBB, as well as prote- olytic degradation. Attenuation of its elimination was likely to result in the increase of cerebral $\mathrm{A} \beta$ deposition, which may facilitate progression of AD [40]. P-gp detoxified cells by exporting hundreds of chemically unrelated toxins but had been implicated in MDR in the treatment of cancers. Substrate promiscuity was a hallmark of P-gp activity, thus a structural description of poly-specific drug-binding was important for the rational design of anti-amyloid accumulation drugs, anticancer drugs and MDR inhibitors. The x-ray structure of apo P-gp at 3.8 angstroms revealed an internal cavity of approximately $6000 \AA^{3}$ with a $30 \AA$ separation of the two nucleotide-binding domains. Two additional P-gp structures with cyclic peptide inhibitors demonstrated distinct drug-binding sites in the internal cavity capable of stereoselectivity that was based on hydrophobic and aromatic interactions. Apo and drug-bound P-gp structures had portals open to the cytoplasm and the inner leaflet of the lipid bilayer for drug entry. The inward-facing conformation represented an initial stage of the transport cycle that was competent for drug binding [41]. Currently, P-gp was identificated as an energy-dependent pump, whereas ATPase activity as an assay in itself was possibly problematical because the assay was based upon one assumption that drug-induced ATP hydrolysis reflects transport by the transporter [16]. There may be many ways in which this activity could be altered, including direct action on the ATP binding domain. Scientists once observed some compounds such as daunomycin and vinblastine inhibit ATPase activity, but increase in others, suggesting that modulation of ATPase activity was highly dependent on experimental conditions and may not correlate well with the ability of P-gp to transport the drug [42-44]. The work of Litman et al. was one of the few studies suggesting that affinity between drugs and ATPase activity has no correlation to LogP, but Surface Area [45]. Because of the less comparability of molecular structures in a training set, our QSAR model possessed more universal significance. However, the precision of the QSAR models was so low that there was still a distance to its application. So a series of organic compounds with similar structures are chosen and consist of a training set, thus the precision of QSAR simulation will be largely increased, while the prediction of the analogues through BBB will be greatly improved.

\section{CONCLUSIONS}

The pathogenesis of $\mathrm{AD}$ is characterized by the aggregation of $\mathrm{A} \beta$ into neurotoxic plaques. P-gp is involved in MDR and in neurodegenerative disorders such as PD, $\mathrm{AD}$ and epilepsy. P-gp mediates the efflux of $\mathrm{A} \beta$ from the brain as well as mediates MDR, while P-gp transports neutral or positively-charged hydrophobic sub- 
strates with consuming energy from ATP hydrolysis. In comparison with the ability of organic molecules permeating across BBB, P-gp binding or MDR-reversal activity of compounds has a negative correlation with LogP. Moreover, P-gp binding or MDR-reversal activity of compounds is mainly proportional to LogMR (Eqs.1 to 5) but inversely proportional to LogP (Eqs.4 and 5). Similarly, ATPase activity of these compounds was largely negatively related to LogP (Eqs.7 to 12) but positively related to MR (Eqs.9 to 11), where most compounds are with $\log \mathrm{P}$ value more than 2.7 . This showed that the P-gp binding capacity of these compounds shared common characteristics with their ATPase hydrolysis, namely their hydrophobic parameters (i.e. $\log \mathrm{P}$ ) and steric parameters (e.g. MR). Additionally, the distribution of organic molecules through BBB was not only influenced by organic solutes themselves, but also related to the properties of the solute-membrane water complex, namely interactions of the molecule with the phospholipide-rich regions of cellular membranes. The ability of organic molecules permeating across BBB was mostly proportional to LogP (Eqs.14 to 18) but inversely proportional to PSA (Eqs.13 to 18), which is consistent with the research results of Chen and co-workers [2], namely the increasing PSA decreased LogBB rapidly while LogP positively related to LogBB. Chen et al. have indicated that the optimum $\log \mathrm{P}$ for designing CNS active drug was about 2.9 and the compound with LogP lower than 2.9 had a positive correlation with $\log \mathrm{BB}$, but the compound with $\log P$ bigger than 2.9 made an unfavorable contribution [2]. It is disclosed that molecules with higher lipophilic would be partitioned into the lipid bilayer more easily with more chances to penetrate BBB, supported by the research result of Wang et al., namely a large number of structurally and functionally diverse compounds as substrates or modulators of P-gp mostly share common structural features, such as aromatic ring structures and high lipophilicity [19]. The LogP not only offered opportunity to penetrate the lipid bilayer, but also gave favorable contribution to binding with P-gp or P450. There may be two reasons for this phenomenon. Firstly, the compounds with higher liposolubility are more vulnerable to cytochrome P450 metabolism, leading to faster clearance [46]. P450 enzymes catalyze the metabolism of a wide variety of endogenous and exogenous compounds including xenobiotics, drugs, environmental toxins, steroids, and fatty acids. Aminated thioxanthones have recently been reported as P-gp inhibitors as well as its interaction with cytochrome P450 3A4 (CYP3A4), as many substrates of P-gp and CYP3A4 are common [47], which could be a major cause of P-gp binding or MDRreversal activity of compounds inversely proportional to LogP. The second reason was related to the mechanism of P-gp action. According to the model proposed by
Higgins and Gottesman [48], after entering into the phospholipid bilayer, compound may interact with P-gp in the inner leaflet of the lipid bilayer. Upon interaction with P-gp, the compound was flipped from the inner leaflet to the outer leaflet of the lipid bilayer. The lipophilic compounds with high LogP entered into cellular membrane easily and intended to retain there, so its opportunity to interact with P-gp increased and then its opportunity to be pumped out of cells enhanced.

In conclusion, the predictive model of BBB partitioning of organic compounds contributed to the discovery of potential AD therapeutic drugs. Moreover, the interaction model of P-gp and modulators for the treatment of multidrug resistance indicates the discovery of some molecules to increase $\mathrm{A} \beta$ clearance from the brain and reduce $\mathrm{A} \beta$ brain accumulation by regulating $\mathrm{BBB} \mathrm{P}-\mathrm{gp}$ in the early stages of $\mathrm{AD}$. Because P-gp is a transporter whose ligands are almost exclusively small molecules, it is not surprising that the pump itself is unable to transport $\mathrm{A} \beta$. Nazer and co-worker have indicated the nonproteolytic clearance of $\mathrm{A} \beta$ via receptor-mediated transport across the BBB and investigated P-gp and the lowdensity lipoprotein receptor-related protein (LRP) involving $\mathrm{A} \beta$ efflux across the BBB [49]. Nevertheless, LRP or P-gp alone was insufficient for non-proteolytic transcytosis of intact $\mathrm{A} \beta$. LRP in transcytosing intact $\mathrm{A} \beta$ across the $\mathrm{BBB}$ may require a co-transporter, such as P-gp [49]. Elucidation of the molecular mechanisms of the potential of LRP and P-gp to efflux cortical $\mathrm{A} \beta$ across $\mathrm{BBB}$ should help to promote rational therapeutic strategy in AD.

\section{ACKNOWLEDGEMENTS}

This work was supported by a grant from Basic Scientific Research Expenses of Central University (020814360012), National Key Technology R\&D Program (2008BAI51B01) and Specialized Research Fund for the Doctoral Program of Higher Education (2012009111 0038).

\section{REFERENCES}

[1] Cheng, Z., Zhang, J., Liu, H., Li, Y., Zhao, Y. and Yang, E. (2010) Central nervous system penetration for small molecule therapeutic agents does not increase in multiple sclerosis- and Alzheimer's disease-related animal models despite reported blood-brain barrier disruption. Drug Metabolism \& Disposition, 38, 1355-1361. doi:10.1124/dmd.110.033324

[2] Chen, Y., Zhu, Q.J., Pan, J., Yang, Y. and Wu, X.P. (2009) A prediction model for blood-brain barrier permeation and analysis on its parameter biologically. Computer Methods and Programs in Biomedicine, 95, 280287. doi:10.1016/j.cmpb.2009.03.006

[3] Miklossy, J. (2011) Alzheimer's disease-A neurospirochetosis. Analysis of the evidence following Koch's and 
Hill's criteria. Journal of Neuroinflammation, 8, 90.

[4] Inoue, M., Konno, T., Tainaka, K., Nakata, E., Yoshida, H.O. and Morii, T. (2012) Positional effects of phosphorylation on the stability and morphology of tau-related amyloid fibrils. Biochemistry, 51, 1396-1406.

[5] Daebel, V., Chinnathambi, S., Biernat, J., Schwalbe, M., Habenstein, B., Loquet, A., Akoury, E., Tepper, K., Müller, H., Baldus, M., Griesinger, C., Zweckstetter, M., Mandelkow, E., Vijayan, V. and Lange, A. (2012) $\beta$ sheet core of tau paired helical filaments revealed by solid-state NMR. Journal of the American Chemical Society, 134, 13982-13989. doi:10.1021/ja305470p

[6] Jeynes, B. and Provias, J. (2011) An investigation into the role of p-glycoprotein in Alzheimer's disease lesion pathogenesis. Neuroscience Letters, 487, 389-393. doi:10.1016/j.neulet.2010.10.063

[7] Vogelgesang, S., Jedlitschky, G., Brenn, A. and Walker, L.C. (2011) The role of the ATP-binding cassette transporter p-glycoprotein in the transport of $\beta$-amyloid across the blood-brain barrier. Current Pharmaceutical Design, 17, 2778-2786. doi:10.2174/138161211797440168

[8] Bartels, A.L. (2011) Blood-brain barrier p-glycoprotein function in neurodegenerative disease. Current Pharmaceutical Design, 17, 2771-2777. doi:10.2174/138161211797440122

[9] Gottesman, M.M. and Pastan, I. (1993) Biochemistry of multidrug resistance mediated by the multidrug transporter. Annual Review of Biochemistry, 62, 385-427.

[10] Kast, C., Canfield, V., Levenson, R. and Gros, P. (1996) Transmembrane organization of mouse p-glycoprotein determined by epitope insertion and immunofluorescence. The Journal of Biological Chemistry, 271, 9240-9248.

[11] Bendayan, R., Lee, G. and Bendayan, M. (2002) Functional expression and localization of p-glycoprotein at the blood brain barrier. Microscopy Research and Technique, 57, 365-380.

[12] Abuznait, A.H., Cain. C., Ingram, D., Burk, D. and Kaddoumi, A. (2011) Up-regulation of p-glycoprotein reduces intracellular accumulation of beta amyloid: Investigation of p-glycoprotein as a novel therapeutic target for Alzheimer's disease. Journal of Pharmacy and Pharmacology, 63, 1111-1118. doi:10.1111/j.2042-7158.2011.01309.x

[13] Kothandan, G., Gadhe, C.G., Madhavan, T., Choi, C.H. and Cho, S.J. (2011) Docking and 3D-QSAR (quantitative structure activity relationship) studies of flavones, the potent inhibitors of p-glycoprotein targeting the nucleotide binding domain. European Journal of Medicinal Chemistry, 46, 4078-4088. doi:10.1016/j.ejmech.2011.06.008

[14] Hartz, A.M., Miller, D.S. and Bauer, B. (2010) Restoring blood-brain barrier p-glycoprotein reduces brain amyloid-beta in a mouse model of Alzheimer's disease. Molecular Pharmacology, 77, 715-723. doi:10.1124/mol.109.061754

[15] Jabeen, I., Pleban, K., Rinner, U., Chiba, P. and Ecker, G.F. (2012) Structure-activity relationships, ligand efficiency, and lipophilic efficiency profiles of benzophenone-type inhibitors of the multidrug transporter p-gly- coprotein. Journal of Medicinal Chemistry, 55, 32613273.

[16] Stouch, T.R. and Gudmundsson, O. (2002) Progress in understanding the structure-activity relationships of pglycoprotein. Advanced Drug Delivery Reviews, 54, 315328. doi:10.1016/S0169-409X(02)00006-6

[17] Sharom, F.J. (1997) The p-glycoprotein efflux pump: How does it transport drugs? The Journal of Membrane Biology, 160, 161-175. doi:10.1007/s002329900305

[18] Li, Y., Wang, Y.H., Yang, L., Zhang, S.W., Liu, C.H. and Yang, S.L. (2005) Comparison of steroid substrates and inhibitors of p-glycoprotein by 3D-QSAR analysis. Journal of Molecular Structure, 733, 111-118.

[19] Wang, R.B., Kuo, C.L., Lien, L.L. and Lien, E.J. (2003) Structure-activity relationship: Analyses of p-glycoprotein substrates and inhibitors. Journal of Clinical Pharmacy and Therapeutics, 28, 203-228.

[20] Wang, Y.H., Li, Y., Yang, S.L. and Yang, L. (2005) An in silico approach for screening flavonoids as p-glycoprotein inhibitors based on a Bayesian-regularized neural network. Journal of Computer-Aided Molecular Design, 19, 137-147. doi:10.1007/s10822-005-3321-5

[21] Chen, C. and Yang, J. (2006) MI-QSAR models for prediction of corneal permeability of organic compounds. Acta Pharmacologica Sinica, 27, 193-204. doi:10.1111/j.1745-7254.2006.00241.x

[22] Kubinyi, H. (1995) Strategies and recent technologies in drug discovery. Pharmazie, 50, 647-662.

[23] Wiese, M. and Pajeva, I.K. (2001) Structure-activity relationships of multidrug resistance reversers. Current $\mathrm{Me}$ dicinal Chemistry, 8, 685-713.

[24] Taub, M.E., Podila, L., Ely, D. and Almeida, I. (2005) Functional assessment of multiple p-glycoprotein (p-gp) probe substrates: Influence of cell line and modulator concentration on p-gp activity. Drug Metabolism \& Disposition, 33, 1679-1687. doi:10.1124/dmd.105.005421

[25] Alka, K. (2003) C-QSAR: A database of 18000 QSARs and associated biological and physical data. Journal of Computer-Aided Molecular Design, 17, 187-196.

[26] Kuo, C.L., Assefa, H., Kamath, S., Brzozowski, Z., Slawinski, J., Saczewski, F., Buolamwini, J.K. and Neamati, N. (2004) Application of CoMFA and CoMSIA 3D-QSAR and docking studies in optimization of mercaptobenzenesulfonamides as HIV-1 integrase inhibitors. Journal of Medicinal Chemistry, 47, 385-399. doi:10.1021/jm030378i

[27] Cramer, R.D., Patterson, D.E. and Bunce, J.D. (1988) Comparative molecular field analysis (CoMFA). 1. Effect of shape on binding of steroids to carrier proteins. Journal of the American Chemical Society, 110, 5959-5967.

[28] Chen, L.J., Lian, G.P. and Han, L.J. (2007) Prediction of human skin permeability using artificial neural network (ANN) modeling. Acta Pharmacologica Sinica, 28, 591600.

[29] Dhainaut, A., Regnier, G., Tizot, A., Pierre A., Leonce, S., Guilbaud, N., Kraus-Berthier, L. and Atassi, G. (1996) New purines and purine analogs as modulators of multidrug resistance. Journal of Medicinal Chemistry, 39, 
4099-4108.

[30] Ford, J.M., Bruggemann, E.P., Pastan, I., Gottesman, M.M. and Hait, W.N. (1990) Cellular and biochemical characterization of thioxanthenes for revesal of multidrug resistance in human and murine cell lines. Cancer Research, 50, 1748-1756.

[31] Schmid, D., Ecker, G., Kopp, S., Hitzler, M. and Chiba, P. (1999) Structure-activity relationship studies of propafenone analogs cased on p-glycoprotein ATPase activity measurements. Biochemical Pharmacology, 58, 1447-1456. doi:10.1016/S0006-2952(99)00229-4

[32] Karelson, M. (2000) Molecular descriptors in QSAR/ QSPR. John Wiley \& Sons, New York.

[33] Karelson, M., Lobanov, V.S. and Katritzky, A.R. (1996) Quantum-chemical descriptors in QSAR/QSPR studies. Chemical Reviews, 96, 1027-1044.

[34] Ponce, Y.M., Garit, J.A., Torrens, F., Zaldivar, V.R. and Castro, E.A. (2004) Atom, atom-type, and total linear indices of the "molecular pseudograph's atom adjacency matrix”: Application to QSPR/QSAR studies of organic compounds. Molecules, 9, 1100-1123. doi:10.3390/91201100

[35] Iyer, M., Mishra, R., Han, Y. and Hopfinger, A.J. (2002) Predicting blood-brain barrier partitioning of organic molecules using membrane-interaction QSAR analysis. Pharmaceutical Research, 19, 1611-1621. doi:10.1023/A:1020792909928

[36] Abraham, M.H., Chadha, H.S. and Mitchell, R.C. (1995) Hydrogen bonding. 36. Determination of blood-brain barrier distribution using octanol-water partition coefficients. Drug Design and Discovery, 13, 123-131.

[37] Abraham, M.H., Takacs-Novak, K. and Mitchell, R.C. (1997) On the partition of ampholytes: Application to blood-brain distribution. Journal of Pharmaceutical Sciences, 86, 310-315. doi:10.1021/js960328j

[38] Bassolino-Klimas, D., Alper, H.E. and Stouch, T.R. (1993) Solute diffusion in lipid bilayer membranes: An atomic level study by molecular dynamics simulation. Biochemistry, 32, 12624-12637. doi:10.1021/bi00210a010

[39] Ma, X.L., Chen, C. and Yang, J. (2005) Predictive model of blood-brain barrier penetration of organic compounds. Acta Pharmacologica Sinica, 26, 500-512. doi:10.1111/j.1745-7254.2005.00068.x
[40] Ohtsuki, S., Ito, S. and Terasaki, T. (2010) Is p-glycoprotein involved in amyloid- $\beta$ elimination across the bloodbrain barrier in Alzheimer's disease? Clinical Pharmacology \& Therapeutics, 88, 443-445.

[41] Aller, S.G., Yu, J., Ward, A., Weng, Y., Chittaboina, S., Zhuo, R., Harrell, P.M., Trinh, Y.T., Zhang, Q., Urbatsch, I.L. and Chang, G. (2009) Structure of p-glycoprotein reveals a molecular basis for poly-specific drug binding. Science, 323, 1718-1722. doi:10.1126/science.1168750

[42] Ambudkar, S.V., Lelong, I.H., Zhang, J., Cardarelli, C.O., Gottesman, M.M. and Pastan, I. (1992) Partial purification and reconstitution of the human multidrug-resistance pump: Characterization of the drug-stimulatable ATP hydrolysis. Proceedings of the National Academy of Sciences of the United States of America, 89, 8472-8476.

[43] Shapiro, A.B. and Ling, V. (1994) ATPase activity of purified and reconstituted p-glycoprotein from Chinese hamster ovary cells. The Journal of Biological Chemistry, 269, 3745-3754.

[44] Doige, C.A., Yu, X. and Sharom, F.J. (1993) The effects of lipids and detergents on ATPase-active p-glycoprotein. Biochimica et Biophysica Acta, 1146, 65-72.

[45] Litman, T., Zeuthen, T., Skovsgaard, T. and Stein, W.D. (1997) Structure-activity relationships of p-glycoprotein interacting drugs: Kinetic characterization of their effects on ATPase activity. Biochimica et Biophysica Acta, 1361, 159-168.

[46] Waterhouse, R.N. (2003) Determination of lipophilicity and its use as a predictor of blood-brain barrier penetration of molecular imaging agents. Molecular Imaging \& Biology, 5, 376-389. doi:10.1016/j.mibio.2003.09.014

[47] Palmeira, A., Sousa, E., Fernandes, M.X., Pinto, M.M. and Vasconcelos, M.H. (2012) Multidrug resistance reversal effects of aminated thioxanthones and interaction with cytochrome P450 3A4. Journal of Pharmacy and Pharmaceutical sciences, 15, 31-45.

[48] Higgins, C.F. and Gottesman, M.M. (1992) Is the multidrug transporter a flippase? Trends in Biochemical Sciences, 17, 18-21.

[49] Nazer, B., Hong, S. and Selkoe, D.J. (2008) LRP promotes endocytosis and degradation, but not transcytosis, of the amyloid-beta peptide in a blood-brain barrier in vitro model. Neurobiology of Disease, 30, 94-102. doi:10.1016/j.nbd.2007.12.005 